\title{
James Hung
}

\section{Estudo do perfil de coagulação em pacientes oncológicos com injúria renal aguda}

Tese apresentada à Faculdade de Medicina da Universidade de São Paulo para obtenção do título de Doutor em Ciências

Programa de Nefrologia

Orientador: Prof. Dr. Luís Yu

São Paulo

2014 


\title{
Dados Internacionais de Catalogação na Publicação (CIP)
}

\author{
Preparada pela Biblioteca da
}

Faculdade de Medicina da Universidade de São Paulo

Creprodução autorizada pelo autor

Hung, James

Estudo do perfil de coagulação em pacientes oncológicos com injúria renal aguda / James Hung. -- São Paulo, 2014.

Tese(doutorado)--Faculdade de Medicina da Universidade de São Paulo. Programa de Nefrologia.

Orientador: Luís Yu.

Descritores: 1.Neoplasias 2.Lesão renal aguda 3.Uremia 4.Coagulação sanguínea 5.Plaquetas 6.Unidades de terapia intensiva 


\section{DEDICATÓRIA}

Aos meus pais, Hung e Lin, que sempre me incentivaram a trilhar o caminho do estudo e que são meu grande exemplo de ética, amor, companheirismo e dedicação aos filhos.

À minha irmã, Anne, pelo companheirismo e pelo apoio em todos os momentos.

À minha esposa, Nirvana, por todo amor e apoio em todos os momentos importantes da minha vida. 


\section{AGRADECIMENTOS}

Ao Dr. Luís Yu, pela orientação, incentivo e oportunidade.

À Tânia Rubia Flores da Rocha, pelo apoio e ensino das técnicas laboratoriais.

Ao Dr. Élbio Antonio D’Amico pela colaboração.

À equipe de enfermagem da nefrologia do ICESP, pelo apoio durante a realização deste trabalho.

Aos pacientes, pela participação no estudo. 
Este trabalho recebeu apoio financeiro da Fundação de Apoio à Pesquisa do Estado de São Paulo, FAPESP, número do processo 2012/00224-3. 
Esta tese está de acordo com as seguintes normas, em vigor no momento desta publicação:

Referências: adaptado de International Committee of Medical Journals Editors (Vancouver).

Universidade de São Paulo. Faculdade de Medicina. Divisão de Biblioteca e Documentação. Guia de apresentação de dissertações, teses e monografias. Elaborado por Anneliese Carneiro da Cunha, Maria Julia de A. L. Freddi, Maria F. Crestana, Marinalva de Souza Aragão, Suely Campos Cardoso, Valéria Vilhena. 3a ed. São Paulo: Divisão de Biblioteca e Documentação; 2011.

Abreviaturas dos títulos dos periódicos de acordo com List of Journals Indexed in Index Medicus. 


\section{SUMÁRIO}

Lista de Abreviaturas e Siglas

Lista de Tabelas

Lista de Figuras

Resumo

Abstract

1. INTRODUÇÃO.

1.1 Fatores de risco para o desenvolvimento de TEV associado ao câncer.....02

1.1.1 Fatores de risco relacionados ao câncer........................................

1.1.2 Fatores de risco relacionados ao tratamento...................................04

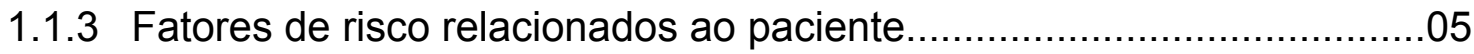

1.2 Potenciais biomarcadores preditores de TEV ................................07

1.3 Modelo celular da coagulação..........................................................

1.3.1 Hemostasia primária................................................................

1.3.2 Hemostasia secundária: formação de trombina e coágulo...................11

1.3.3 Mecanismo de controle da ativação da coagulação..............................12

1.3.4 Sistema fibrinolítico.................................................................... 12

1.4 Avaliação laboratorial da hemostasia...............................................13

1.4.1 Tempo de protrombina (TP) ................................................. 13

1.4.2 Tempo de tromboplastina parcial ativada (TTPa) ..............................15

1.4.3 Tempo de trombina (TT) ..............................................................

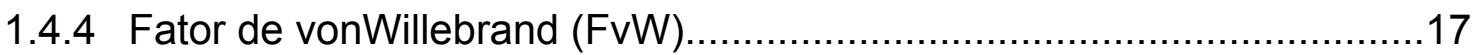

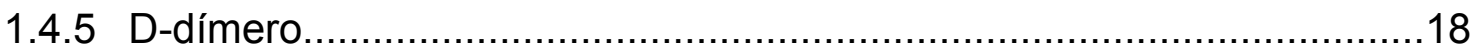

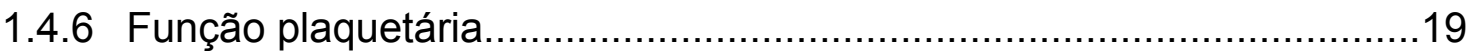

1.4.6.1 Adesão plaquetária.................................................................... 19

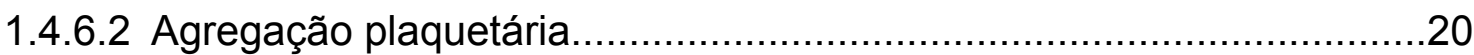

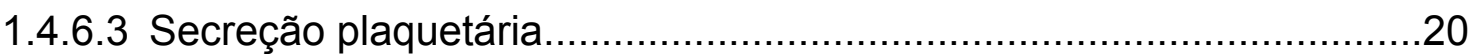

1.4.6.4 Outros processos bioquímicos envolvidos na agregação e secreção plaquetária......................................................................... 21

1.4.6.5 Avaliação da função plaquetária................................................21

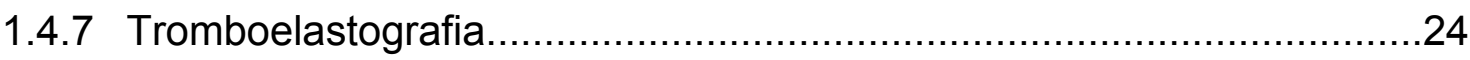

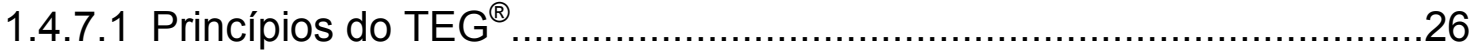

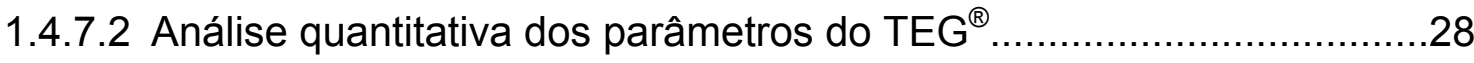

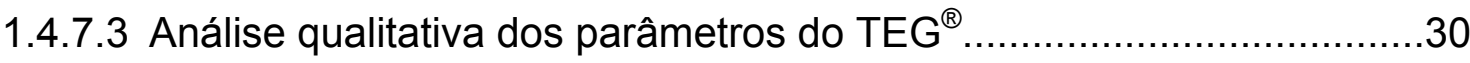


1.4.8 Teste da geração de trombina................................................ 32

1.5 Pacientes oncológicos e injúria renal aguda.................................34

1.5.1 Classificação da injúria renal aguda...........................................

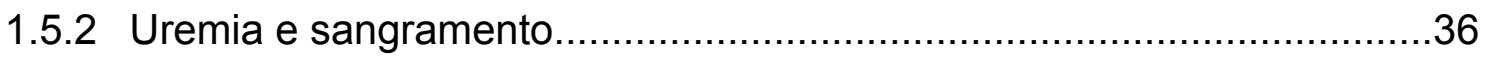

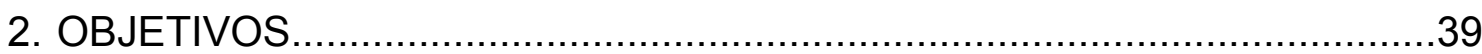

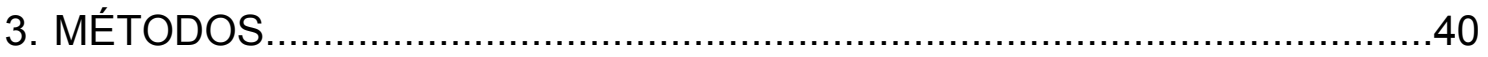

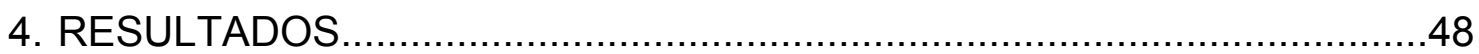

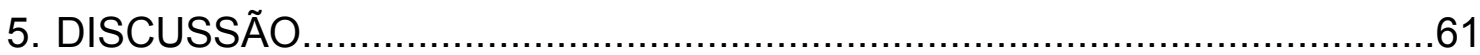

6. CONCLUSÕES

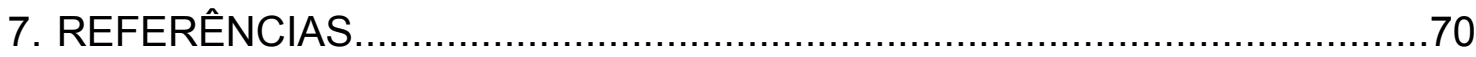




\section{Lista de Abreviaturas e Siglas}

ADP adenosina difosfato

AKIN acute kidney injury network

ALT alanina aminotransferase

AS average size, tamanho médio

AST aspartato aminotransferase

AT anti-trombina

ATP adenosina trifosfato

AVC acidente vascular cerebral

Cai cálcio iônico

$\mathrm{Cl}$ índice de coagulação

COX ciclo-oxigenase

CVC cateter venoso central

ETP potencial endógeno de trombina

FvW fator de vonWillebrand

GP glicoproteína

IMC índice de massa corporal

INR relação normatizada internacional

IRA injúria renal aguda

ISI índice de sensibilidade internacional

$\mathrm{K}$ potássio

MA amplitude máxima

$\mathrm{Mg} \quad$ magnésio

$\mathrm{Na} \quad$ sódio

OR odds-ratio

$\mathrm{P} \quad$ fósforo

PCR proteína $C$ reativa

RFG ritmo de filtração glomerular

rpm rotações por minuto

SC surface covered, superfície coberta

TAFla inibidor de fibrinólise ativável por trombina

TEG tromboelastografia 
TEV tromboembolia venosa

TF fator tecidual

TP tempo de protrombina

t-PA plasminogênio tecidual

TTPa tempo de tromboplastina parcial ativada

TT tempo de trombina

u-PA uroquinase

UTI unidade de terapia intensiva 


\section{Lista de Tabelas}

Tabela 1 Características dos pacientes e escore de risco. .08

Tabela 2 Modelo preditivo de TEV associado à quimioterapia baseado no escore total

Tabela 3 Situações em que o D-dímero pode estar aumentado.................18

Tabela 4 Impact- ${ }^{\circledR}$ : parâmetros e interpretação................................23

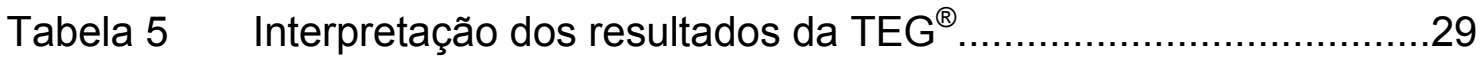

Tabela 6 Dados demográficos e clínicos.........................................49

Tabela $7 \quad$ Tipos de tumores dos pacientes estudados.............................52

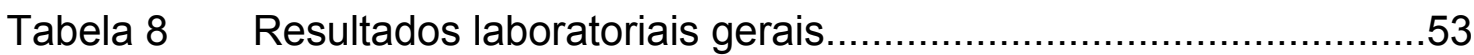

Tabela 9 Resultados laboratoriais hematológicos...............................54

Tabela 10 Avaliação da adesão e agregação plaquetária pelo Impact- $R^{\circledR} \ldots 55$

Tabela 11 Resultados da tromboelastografia......................................55

Tabela 12 Teste da geração de trombina..............................................56

Tabela 13 Descrição dos dados demográficos e clínicos segundo mortalidade....................................................................

Tabela 14 Resultados laboratoriais gerais e mortalidade.........................58

Tabela 15 Descrição dos exames laboratoriais segundo mortalidade e resultado dos testes estatísticos.

Tabela 16 Descrição das variáveis de adesão e agregação plaquetária, geração de trombina e tromboelastografia segundo mortalidade. 59

Tabela 17 Variáveis que influenciaram na mortalidade, após regressão logística. 


\section{Lista de Figuras}

Figura 1 Modelo clássico da cascata de coagulação............................10

Figura 2 Modelo celular da coagulação............................................13

Figura 3 Equipamento utilizado para avaliação da função plaquetária......22

Figura 4 Avaliação da função plaquetária: princípio do cone e placa.........23

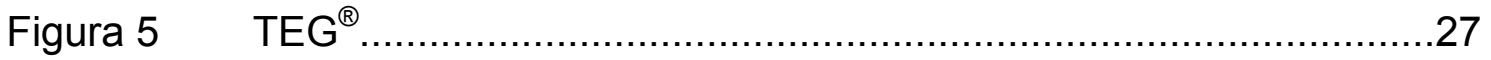

Figura 6 Representação gráfica da coagulação...............................27

Figura $7 \quad$ Mecanismo da tromboelastografia.........................................28

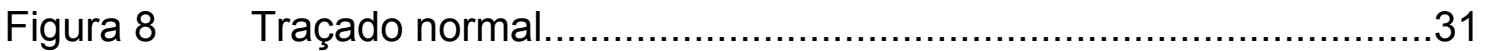

Figura 9 Hipercoagulante (R e K diminuídos; MA e ângulo aumentados)..31

Figura 10 Hipocoagulante (R prolongado; K, ângulo e MA diminuídos).......31

Figura 11 Fibrinólise ( $R$ normal; $K$, ângulo e MA reduzidos; MA

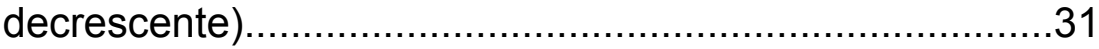

Figura 12 Aparelho para análise da geração de trombina..........................33

Figura 13 Curva para análise da geração de trombina...............................33 


\section{Lista de Gráficos}

Gráfico 1 Mortalidade segundo grau de IRA (AKIN) .............................52 


\section{RESUMO}

Hung J. Estudo do perfil de coagulação em pacientes oncológicos com injúria renal aguda. São Paulo: Faculdade de Medicina, Universidade de São Paulo; 2014.

Introdução: Pacientes com câncer frequentemente apresentam distúrbios de coagulação, que podem se manifestar clinicamente na forma de trombose ou simples alterações nos exames de hemostasia. A injúria renal aguda (IRA) é comum em pacientes oncológicos e pode ocorrer como consequência do próprio câncer; do tratamento; ou sepse secundária à imunossupressão causada pela quimioterapia. A IRA é encontrada em até $67 \%$ dos pacientes em UTI e está associada à alta mortalidade, além de resultar em maior custo e tempo na internação hospitalar. O sangramento causado pela uremia é uma complicação que pode ocorrer em pacientes com falência renal. O efeito da interação da IRA na coagulação dos pacientes com câncer ainda não está elucidado. Objetivo: Estudar o perfil de coagulação dos pacientes oncológicos com sepse grave ou choque séptico e avaliar o efeito da IRA na coagulação destes pacientes. Critérios de inclusão: pacientes maiores de 18 anos, portadores de tumores sólidos ou hematológicos, admitidos na UTI do ICESP com diagnóstico de sepse grave ou choque séptico. Critérios de exclusão: pacientes com insuficiência renal crônica em programa regular de diálise e pacientes com coagulopatia prévia ou história familiar de coagulopatia. Métodos: Foram estudados pacientes admitidos no período de agosto de 2012 a janeiro de 2014. A coleta de exames de sangue foi realizada no momento da admissão na UTI e ao apresentar IRA, pelo critério AKIN. O perfil de coagulação estudado compreendeu: TP, TTPa, D-dímero, fibrinogênio, fator VIII, avaliação de adesão e agregação plaquetária com Impact- ${ }^{\circledR}$, tromboelastografia e avaliação da geração de trombina. Dados clínicos e epidemiológicos foram obtidos a partir dos prontuários. Resultados: foram incluídos 144 pacientes na análise final. As características foram semelhantes nos grupos em relação à idade, IMC, sexo, e comorbidades tais como, hipertensão arterial e diabetes mellitus. Os testes convencionais de coagulação (TP, TT, TTPa) estavam alterados no grupo com IRA. Entretanto, a análise da coagulação pela tromboelastografia não demonstrou diferença entre os grupos com IRA comparados com o grupo que não apresentou IRA. A análise da função plaquetária pelo Impact- $R^{\circledR}$ revelou que a uremia não piorou a adesão e agregação plaquetária. Observou-se que houve menor geração de trombina e nível de Ddímero mais elevado no grupo com IRA AKIN3. Regressão logística multivariada demonstrou que a necessidade de ventilação mecânica, nível de proteína $C$ reativa mais elevada, e IRA estavam associados à maior mortalidade. Maior geração de trombina estava associada à menor mortalidade. Conclusão: a IRA em pacientes críticos oncológicos com sepse ou choque séptico está associada ao alargamento dos testes de coagulação convencionais (TP, TT, TTPa), devido à deficiência de alguns fatores de coagulação. Entretanto, a tromboelastografia, que analisa a hemostasia global do paciente, apresentou resultado normal devido à hiperativação da função plaquetária. O acúmulo de toxinas urêmicas, devido à injúria renal aguda, não levou à piora da função plaquetária. Pelo contrário, houve até um aumento na agregação e adesão plaquetária nos pacientes oncológicos.

Descritores: 1. Neoplasias; 2. Injúria renal aguda; 3. Uremia; 4. Coagulação; 5. Plaquetas; 6 . Unidade de terapia intensiva 


\section{ABSTRACT}

Hung, J. Study of coagulation profile in cancer patients with acute kidney injury. São Paulo: "Faculdade de Medicina, Universidade de São Paulo; 2014.

Introduction: Patients with cancer often have coagulation disorders, which may manifest clinically as thrombosis or simple changes in hemostasis tests. Acute kidney injury (AKI) is frequent in cancer patients and may occur as a consequence of the cancer itself or due to the treatment or sepsis secondary to immunosuppression caused by chemotherapy. AKI is found in up to $67 \%$ of ICU (Intensive Care Unit) patients, associated with high mortality, and resulting in increased cost and stay in the hospital. Bleeding caused by uremia is a complication that can occur in patients with renal failure. The effect of the interaction between $\mathrm{AKI}$ and coagulation in cancer patients has not been yet elucidated. Objectives: To analyse the coagulation profile in cancer patients with severe sepsis or septic shock and evaluate the effect of AKI in the coagulation profile. Inclusion criteria: patients older than 18 years old with solid or hematological tumors admitted to the ICU, diagnosed with severe sepsis or septic shock. Exclusion criteria: patients with chronic renal failure undergoing regular dialysis program and patients with previous coagulopathy or family history of coagulopathy. Methods: We studied patients admitted to the ICU between August 2012 and January 2014. The collection of blood samples was performed at the time of ICU admission and at the time of AKI, according to the AKIN criteria. The coagulation profile included: PT, aPTT, D-dimer, fibrinogen, factor VIII, platelet adhesion and aggregation, thromboelastography and evaluation of thrombin generation. Clinical and epidemiological data were obtained from medical records. Results: A total of 144 patients was included in the final analysis. The following characteristics were similar between groups: age, BMI, gender, and comorbidities such as hypertension and diabetes mellitus. Conventional coagulation tests results (PT, TT, aPTT) were altered in the group with AKI. However, analysis of coagulation by thromboelastography showed no difference between groups with AKI compared with the group without AKI. Platelet function analysis by Impact- ${ }^{\circledR}$ revealed that uremia has not worsened platelet adhesion and aggregation. It was observed that there was less thrombin generation and higher D-dimer level in the AKIN3 group. Multivariate logistic regression showed that the need for mechanical ventilation, higher level of C-reactive protein, and AKI were associated with higher mortality. Higher thrombin generation was associated with lower mortality. Conclusions: AKI in critically ill cancer patients with sepsis or septic shock is associated with abnormalities of conventional coagulation tests (PT, TT, aPTT) due to some coagulation factors deficiency. However, thromboelastography which analyzes the global hemostasis presented a normal result, probably due to platelet function hyperactivation. Furthermore, the accumulation of uremic toxins due to acute kidney injury did not worsen platelet function in cancer patients.

Descriptors: 1. Neoplasias 2. Acute kidney injury 3. Uremia 4. Blood coagulation 5. platelets 6 . Intensive care unit 


\section{INTRODUÇÃO}

Câncer é considerado um estado pró-trombótico. Em 1868, Trousseau descreveu a relação entre câncer e trombose venosa. Sabe-se que pacientes com câncer têm risco aumentado de 2 a 7 vezes para desenvolver tromboses (1). Uma meta-análise recente mostrou que aproximadamente $15 \%$ dos pacientes com tromboembolia venosa (TEV) será diagnosticado com câncer nos próximos 12 meses (2). O risco aumentado de trombose nesses pacientes está associado a alterações do fluxo sanguíneo, na constituição sanguínea e na lesão do endotélio vascular, conhecida como a tríade de Virchow (3):

- Estase: paciente acamado e imobilizado, compressão extrínseca dos vasos sanguíneos pelo tumor;

- Componentes sanguíneos: o tumor e os macrófagos produzem substâncias pró-coagulantes e citocinas inflamatórias;

- Lesão endotelial: invasão direta do tumor, inserção de cateteres, quimioterapia, eritropoetina e agentes anti-angiogênicos.

O tromboembolismo venoso é freqüente e se manifesta como trombose venosa profunda ou embolia pulmonar. Pacientes com câncer constituem cerca de $20 \%$ dos casos de TEV (4). Os eventos arteriais, incluindo acidente vascular cerebral $(A \vee C)$ e infarto do miocárdio, também são mais frequentes nos pacientes oncológicos (5). TEV constitui-se na segunda causa de morte em pacientes com câncer (6) e a causa mais comum de óbito no período perioperatório (7). Além disso, TEV em câncer está associada com um risco anual 
de $21 \%$ de TEV recorrente, de $12 \%$ de risco anual de complicações de sangramentos, necessidade de anticoagulação por longos períodos e interrupção de quimioterapia (7).

O estado pró-coagulante do câncer é secundário a eventos específicos oncogênicos. A ativação da cascata de coagulação está integralmente relacionada ao processo do crescimento tumoral, metástase e angiogênese. Alguns estudos mostraram que defeitos do fibrinogênio e ativação plaquetária reduziram o potencial metastático. Isso levou ao interesse nos estudos do efeito anticancerígeno ao se interromper a cascata de coagulação. Outros fatores têm contribuído para o aumento de TEV, como as novas drogas para o tratamento do câncer, particularmente os agentes antiangiogênicos (7).

\subsection{Fatores de risco para o desenvolvimento de TEV associado ao câncer}

Khorana e cols. descreveram os fatores de risco para o desenvolvimento de TEV associado ao câncer e validaram um modelo de risco que ajuda a identificar os pacientes oncológicos com maior risco de desenvolvimento de $\operatorname{TEV}(8)$

Os fatores de risco são relacionados ao câncer, ao tratamento e ao paciente. 


\subsubsection{Fatores de risco relacionados ao câncer}

O sítio primário do câncer é considerado um fator de risco para TEV. Assim, pacientes com câncer de pâncreas, estômago, útero, rim, pulmão, cérebro e hematológicos são os que estão associados a maior incidência de TEV (8).

Grandes estudos de coorte identificaram que o estágio da doença influencia o risco de TEV, principalmente quando apresenta um estado funcional clínico ruim. Nos pacientes com estado funcional preservado, alguns estudos demonstraram que não houve associação entre estágio do câncer e TEV (8).

O risco de TEV é maior no período imediato ao diagnóstico. Em estudo recente (1), demonstrou-se que o odds-ratio ajustado para o desenvolvimento de TEV nos primeiros três meses era 53,5 , declinando posteriormente para 14,3 e 3,6 após 1 ano e 3 anos, respectivamente. Muitas intervenções terapêuticas ocorrem nesse período inicial, o que certamente contribui para o aumento do risco de TEV. Pode-se citar que, em pacientes com linfoma de grandes células $B$, houve uma incidência de $82 \%$ de eventos de TEV nos primeiros três ciclos de quimioterapia (9) e que $45 \%$ dos eventos vasculares de pacientes com câncer de pulmão ocorreram nos primeiros dois ciclos da quimioterapia (10). 


\subsubsection{Fatores de risco relacionados ao tratamento}

A quimioterapia está associada ao risco aumentado de 2 a 6 vezes no desenvolvimento de TEV em comparação com a população geral $(11,12)$. A incidência de TEV aumentou cerca de 47\% no período de 1995 a 2003 em pacientes internados que receberam quimioterapia (13). Agentes quimioterápicos específicos estão associados à TEV, como os quimioterápicos contendo platina (14). A talidomida também está associada ao TEV, em cerca de 12 a 28\%, quando usada em combinação com dexametasona ou outro quimioterápico, como a doxorrubicina. A lenalidomida também está associada com TEV. O tratamento com bevaclizumabe está associado também com aumento de TEV e inclusive, de eventos arteriais (15).

Pacientes oncológicos frequentemente recebem agentes estimuladores da eritropoiese para o tratamento da anemia. Em um estudo randomizado controlado, observou-se que dos 3.728 pacientes tratados com darbopoetina ou eritropoetina, 229 pacientes apresentaram eventos tromboembólicos comparados com 118 pacientes dos 3.041 pacientes-controle (16). Por conta disto, transfusões sanguíneas são realizadas como alternativa aos agentes estimuladores da eritropoiese para o tratamento da anemia. Entretanto, uma análise retrospectiva de pacientes oncológicos hospitalizados e que receberam transfusão sanguínea mostrou associação com aumento de TEV, eventos arteriais e mortalidade intra-hospitalar (17).

O ato cirúrgico e o período perioperatório são reconhecidamente fatores de risco para TEV. Em um estudo recente com pacientes oncológicos cirúrgicos, foram identificados os seguintes fatores de risco para TEV: idade 
maior que 60 anos, antecedentes de TEV, câncer em fase avançada, tempo de anestesia superior a 2 horas e período acamado superior a 3 dias (18).

A hospitalização aumenta substancialmente o risco de TEV nos pacientes com câncer (12). Em estudo recente, o risco foi de 4\% por internação, podendo variar até $18 \%$ dependendo do subgrupo estudado $(5,13)$.

Os acessos vasculares, como o cateter venoso central (CVC), são amplamente utilizados em pacientes com câncer durante o tratamento quimioterápico. A incidência de trombose venosa profunda sintomática relacionada ao uso do cateter varia de 0,3 até $28 \%$, enquanto que a trombose venosa profunda associada ao cateter observada após busca ativa por venografia variou de 27 a 66\% (19). Um estudo prospectivo recente analisando mais de 400 pacientes com câncer e CVC, observou que 4,3\% deles desenvolveram trombose venosa profunda relacionada ao CVC. Os fatores de risco para complicações relacionadas ao CVC incluem: mais de uma tentativa para inserção do cateter, inserção prévia de cateter, inserção do CVC no lado esquerdo do paciente e posição da ponta do cateter em região da veia cava superior comparado com átrio direito $(20,21)$.

\subsubsection{Fatores de risco relacionados ao paciente}

A presença de comorbidades aumenta o risco de TEV. Nos pacientes hospitalizados, são comorbidades fortemente associadas à TEV: infecção, tromboembolismo arterial, nefropatia, pneumopatia e anemia (13). Anemia e obesidade estão relacionadas à TEV em pacientes ambulatoriais (14). 
Antecedentes históricos de eventos trombóticos constituem fator de risco para TEV. Em estudo com pacientes submetidos à cirurgia, aqueles com história prévia de trombose tinham um risco maior de desenvolver nova trombose (18). Trombose local predispõe a eventos sistêmicos, como demonstrado em um estudo retrospectivo de pacientes com carcinoma hepatocelular, nos quais aqueles que tinham trombose venosa portal apresentavam um aumento de 2,6 vezes de desenvolver TEV (22).

Pacientes com câncer e mutação do fator $V$ de Leiden ou presença do gene da protrombina apresentaram maior chance de TEV (ref).

Pacientes hospitalizados com câncer e idade superior a 65 anos também apresentam risco maior de TEV (13). No contexto cirúrgico, idade superior a 60 anos também está relacionada à TEV (18). Entretanto, em pacientes ambulatoriais, a idade não foi fator de risco para TEV, provavelmente devido ao melhor estado funcional.

Muitos estudos não têm demonstrado gênero como fator de risco para TEV. Entretanto, um estudo de pacientes hospitalizados mostrou discreto aumento do risco em pacientes do sexo feminino (13).

A imobilidade, que leva à estase venosa, é reconhecida como fator de risco para TEV. Em um estudo prospectivo de pacientes com câncer de pulmão, $31 \%$ dos pacientes com estado funcional ruim em quimioterapia apresentou TEV comparado com $15 \%$ dos pacientes em bom estado funcional. Pacientes cirúrgicos acamados por mais de 3 dias também têm risco maior em desenvolver TEV (18). 


\subsection{Potenciais biomarcadores preditores de TEV em pacientes com câncer}

Alguns estudos mostraram que certos exames laboratoriais podem ser utilizados como biomarcadores preditores de TEV em pacientes com câncer.

Em um estudo prospectivo observacional (23) de pacientes em tratamento com quimioterapia, observou-se que o número de plaquetas superior a $350.000 / \mathrm{mm}^{3}$ no período pré-quimioterapia estava associado ao risco maior de TEV. Leucócitos pré-quimioterapia superior a $11.000 / \mathrm{mm}^{3}$ também estava associado a um risco maior (24).

O fator tecidual (TF) é o iniciador fisiológico da cascata de coagulação. Este fator está expresso em uma série de neoplasias e muitos estudos atualmente têm focado no papel deste fator tecidual no desenvolvimento de trombose (25). O TF pode ser avaliado de diversas maneiras: através do grau de expressão no tumor por imunohistoquímica, pela dosagem de níveis sistêmicos de TF ou pela atividade do TF.

O D-dímero é um marcador da ativação da hemostasia e está elevado nos pacientes com câncer. D-dímero elevado se mostrou como fator preditor de TEV no período pós-operatório e de TEV recorrente (26).

A proteína $C$ reativa é um marcador de inflamação e considerado como marcador de eventos cardiovasculares e mortalidade. Em um estudo unicêntrico, a proteína C reativa elevada esteve associada ao risco de desenvolvimento de TEV (14).

Um modelo estatístico para identificar pacientes de alto risco para TEV foi validado e publicado recentemente (Tabelas 1 e 2) (24). Os fatores de risco 
foram estudados em uma coorte de 2.701 pacientes ambulatoriais com câncer e que estavam iniciando quimioterapia. O modelo de risco foi validado posteriormente em uma coorte independente de 1.365 pacientes do mesmo estudo. Cinco fatores preditivos de risco foram identificados:

1. Sítio primário do câncer (e o tipo de câncer)

2. Plaquetas $>350.000 / \mathrm{mm}^{3}$,

3. Hemoglobina $<10 \mathrm{~g} / \mathrm{dL}$ (ou uso de agentes estimuladores da eritropoiese)

4. Leucócitos $>11.000 / \mathrm{mm}^{3}$

5. IMC $>35 \mathrm{~kg} / \mathrm{m}^{2}$

Tabela 1: Características dos pacientes e escore de risco

\begin{tabular}{l|c}
\hline Características dos pacientes & Escore de risco \\
\hline \multicolumn{1}{c}{ Sítio primário do câncer } \\
\hline Altíssimo risco (estômago, pâncreas) & 2 \\
\hline Alto risco (pulmão, linfoma, ginecológico, testicular) & 1 \\
\hline Pré-quimioterapia: plaquetas $\geq 350.000 / \mathrm{mm}^{3}$ & 1 \\
\hline Hemoglobina $<10 \mathrm{~g} / \mathrm{dL}$ ou uso de eritropoetina & 1 \\
\hline Pré-quimioterapia: leucócitos $\geq 11 \times 10^{9} / \mathrm{L}$ & 1 \\
\hline IMC $\geq 35 \mathrm{~kg} / \mathrm{m}^{2}$ & 1 \\
\hline
\end{tabular}


Tabela 2: Modelo preditivo de TEV associado à quimioterapia baseado no escore total

\begin{tabular}{c|c|c}
\hline Escore total & Categoria de risco & Risco de TEV sintomático \\
\hline 0 & Baixo & $0,3-0,8 \%$ \\
\hline 1,2 & Intermediário & $1,8-2 \%$ \\
\hline$\geq 3$ & alto & $6,7-7,1 \%$ \\
\hline
\end{tabular}

\subsection{Modelo celular da coagulação}

O clássico modelo de coagulação descreve uma cascata de reações envolvendo ativação de vários fatores de coagulação ao longo da via intrínseca e extrínseca (Figura 1). De acordo com esse modelo, o estímulo tanto da via extrínseca quanto da via intrínseca pode resultar na produção de grandes quantidades de trombina e subsequente formação de coágulo de fibrina. Entretanto, esse modelo descreve apenas o fenômeno da interação dos fatores de coagulação in vitro e não explica adequadamente o fenômeno da hemostasia in vivo, no qual ocorre a interação entre os fatores de coagulação e as células $(27,28)$. 
Via Intrínseca

\section{Via Extrínseca}

\section{Fator XII}

Cininogênio de baixo peso molecular

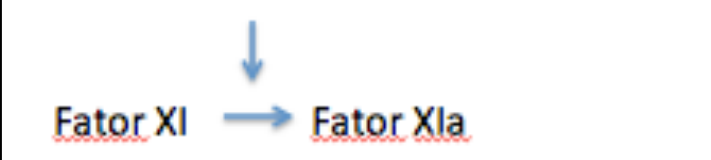
Fator $X 1 \longrightarrow$ Fator Xla
Fator IX $\longrightarrow$ Fator Ixa Fator Vllla

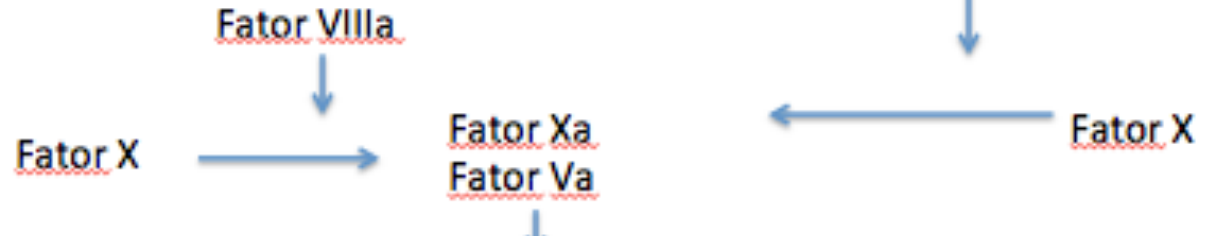

Fator II

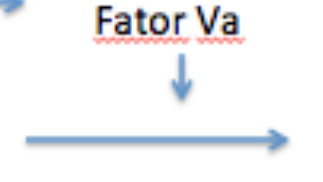

fibrinogênio

\section{Fator lla}

Fator Vlla

Fator tecidual
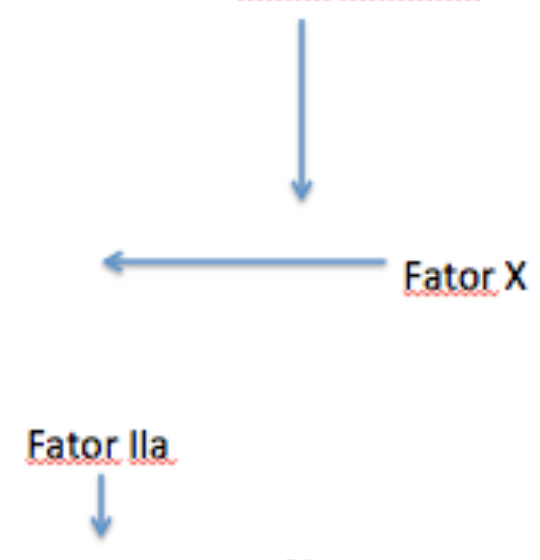

Adaptado de Hoffman M, Blood Reviews (2003) 17, S1-S5.

Figura 1. Modelo clássico da cascata de coagulação

Atualmente, o desenvolvimento do modelo celular de coagulação (Figura 2) permite melhor entendimento do processo da hemostasia in vivo. Apesar do processo primário e secundário da hemostasia serem intimamente ligados, serão explicados de forma separada.

\subsubsection{Hemostasia primária}

A exposição do colágeno presente no subendotélio desencadeia a adesão plaquetária e sua alteração conformacional. Há ainda a secreção dos 
grânulos plaquetários e agregação plaquetária inicial. Essas etapas iniciais são facilitadas pela atividade de ponte do fator de vonWillebrand (FvW), pela ligação do fibrinogênio aos receptores GPIIb/IIla plaquetários e pela pequena quantidade de trombina formada durante o processo de iniciação da coagulação $(27,28)$.

\subsubsection{Hemostasia secundária: formação de trombina e coágulo}

Durante a fase de iniciação da coagulação, o fator tecidual (TF) exposto se liga ao fator VIla (FVIla) circulante, formando o complexo TF/FVIla. Esse complexo leva à formação de fator $\mathrm{Va}$ e Xa, que ativam a conversão de pequena quantidade de protrombina à trombina.

Durante a fase de amplificação e propagação da coagulação, a trombina inicialmente formada ativa plaquetas aderidas, facilitando a liberação de grânulos e a ligação com fator de coagulação, fibrinogênio e cálcio. Além disso, a trombina inicial permite a formação de fator VIIla, promovendo a formação adicional de fator Xa. Em paralelo, fator Xla induzido pela trombina ativa o fator IXa que, por sua vez, aumenta a formação do fator Xa. Por fim, a trombina ativa o fator $\mathrm{Va}$, na presença de fator $\mathrm{Xa}$ e cálcio ligado à superfície das plaquetas ativadas, fazendo com que grandes quantidades de protrombina sejam convertidas a trombina.

A maior parte da trombina é gerada durante a formação de coágulo. Cada plaqueta ativada expõe milhares de receptores GPIIb/IIla para uma efetiva ligação com fibrinogênio, desencadeando agregação plaquetária 
primária. Quando houver produção suficiente de trombina, o fibrinogênio é clivado, resultando em monômeros de fibrina, que se polimerizam espontaneamente. O fator XIIla e o inibidor de fibrinólise ativável por trombina (TAFla) estabilizam o coágulo. O fator XIIla catalisa a ligação cruzada entre fibrinas (fibrin cross-linking). TAFla reduz a fibrinólise através da redução de sítios de ligação para o plasminogênio e ativador de plasminogênio tecidual (tPA) $(27,28)$.

\subsubsection{Mecanismo de controle da ativação da coagulação}

A formação inicial de trombina é limitada pelo TFPI (tissue factor pathway inhibitor) e antitrombina (AT), que neutralizam o complexo TF/FVIla. A heparina endógena ou exógena servem de cofator para aumentar a atividade de AT. A trombina também se liga à fibrina formada, assim, níveis excessivos de trombina são limitados pela formação da fibrina intacta.

A ligação da trombina à trombomodulina endotelial reduz o efeito prócoagulante da trombina e ativa a proteína C circulante. A proteína C juntamente com o seu cofator, a proteína $S$, reduz a formação de trombina inativando o fator VIIla e Va $(27,28)$.

\subsubsection{Sistema fibrinolítico}

A ativação do plasminogênio circulante para plasmina pelo t-PA, uroquinase (u-PA), fator Xlla ou calicreína resulta na lise da fibrina, formação 
de D-dímero e até a degradação de fibrinogênio. O inibidor de ativador da plasmina (PAI, plasmin activator inhibitor) inativa o ativador de plasmina e os fatores XIIla e TAFla.

Resumidamente, a trombina é a enzima-chave motora do processo de formação do coágulo e o fibrinogênio é o principal substrato durante a coagulação. As plaquetas, por sua vez, contribuem para a formação de trombina e são também substratos necessários para a coagulação $(27,28)$.

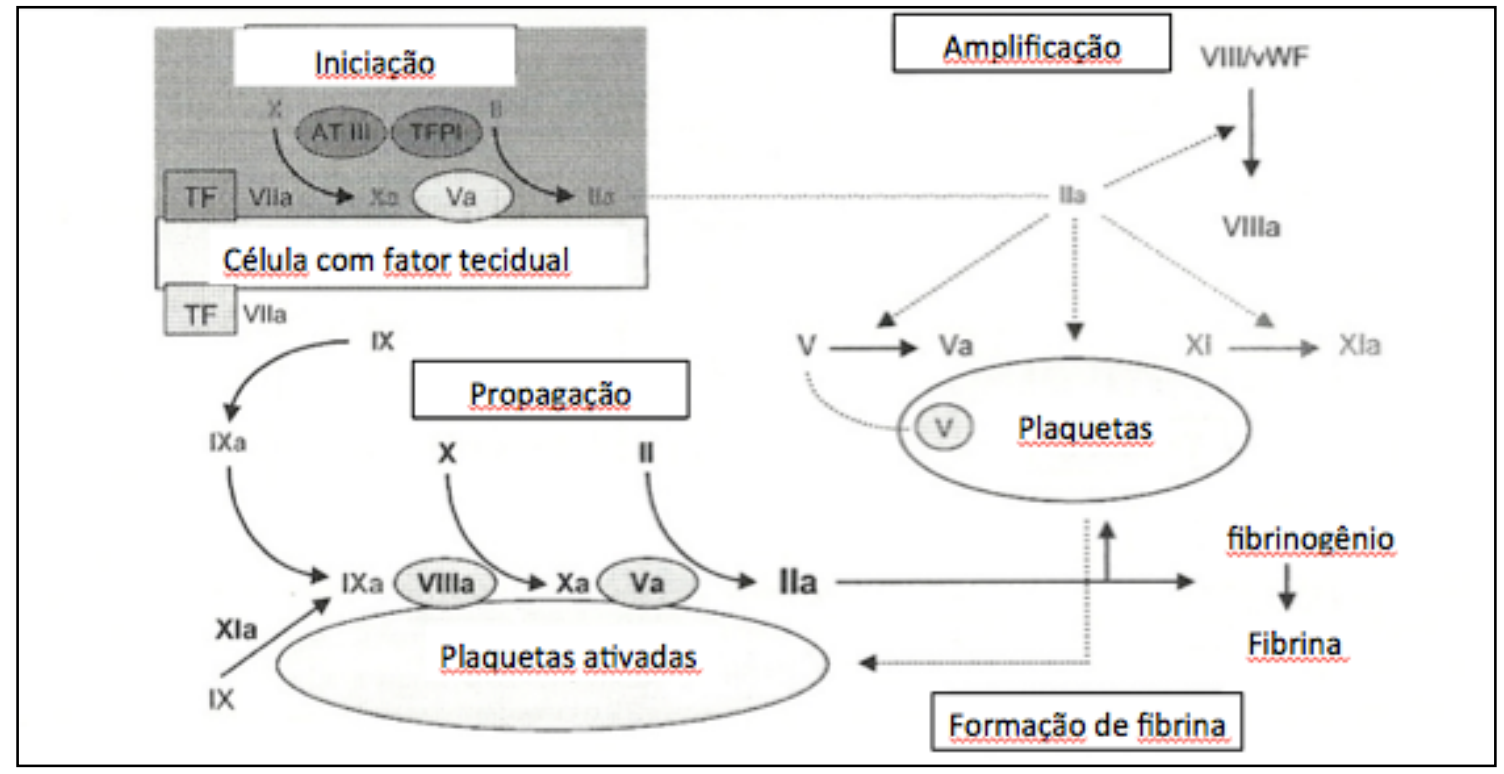

Adaptado de Hoffman M, Blood Reviews (2003) 17, S1-S5.

Figura 2: Modelo celular de coagulação

\subsection{Avaliação laboratorial da hemostasia}

\subsubsection{Tempo de protrombina (TP)}

O TP avalia as vias extrínseca e comum da coagulação. É dependente da integridade dos fatores VII, V, II e X. O teste consiste na adição de 
tromboplastina ao plasma (fator tecidual) e posterior mensuração do tempo de coágulo. O fator tecidual ativa o fator VII, ativando a via extrínseca, formando o complexo protrombinase ancorado pela tromboplastina, que culmina na geração de trombina. Esta atua na molécula de fibrinogênio, formando a fibrina, que será estabilizada pelo fator XIII.

Um TP prolongado pode indicar deficiências hereditárias, principalmente do fator VII, ou adquiridas, como deficiência de vitamina $\mathrm{K}$, doença hepática, coagulação intravascular disseminada ou uso de medicamentos. É o teste de escolha para monitorizar o uso de anticoagulantes orais antivitamina $\mathrm{K}$.

O TP é mais sensível à deficiência do fator VII e tem menor sensibilidade aos fatores da via comum e na deficiência de fibrinogênio. Entretanto, na hipofibrinogenemia grave (abaixo de $100 \mathrm{mg} / \mathrm{dl}$ de fibrinogênio) e na afibrinogenemia (ausência de fibrinogênio), o TP encontra-se alargado e incoagulável, respectivamente. O teste de mistura com plasma normal deve ser realizado para identificar se o prolongamento ocorre por deficiência de fator ou presença de inibidor. Se houver correção do TP, deve-se determinar o fator VII. Caso esteja normal, deve-se avaliar o resultado do TTPa e então testar os fatores V, II e X. Não havendo correção do TP na mistura, deve-se fazer a pesquisa de inibidores dirigidos contra fatores da via extrínseca e comum. Os inibidores de fator VII são raros.

A tromboplastina ou fator tecidual pode ser extraído de tecido cerebral humano, de porco ou coelho. Atualmente, o fator tecidual recombinante vem sendo cada vez mais utilizado e o TP mensurado com essa tromboplastina 
parece ser mais confiável na identificação de variantes de deficiência de fator VII.

A origem da tromboplastina interfere na sua sensibilidade, por isso, os resultados de um TP do mesmo paciente na mesma amostra podem variar de um laboratório para outro. Em função disso, criou-se uma tromboplastina padrão. Os reagentes para TP devem ser comparados à tromboplastina padrão e, essa comparação é chamada de Índice de Sensibilidade Internacional (ISI).

A relação normatizada internacional (INR) foi instituída pela Organização Mundial de Saúde para padronizar as diferenças de resultados de TP entre os vários laboratórios. Essas diferenças ocorrem devido à diferença de métodos, aparelhos e tromboplastinas. Todos os fabricantes de tromboplastina devem determinar o ISI mediante a padronização de sua tromboplastina frente a uma tromboplastina de referência internacional. Quanto mais próximo de 1,0 for o ISI, mais sensível é a tromboplastina (29).

\subsubsection{Tempo de tromboplastina parcial ativada (TTPa)}

O TTPa é o teste de triagem para a avaliação dos fatores das vias intrínsecas e comum da coagulação. Detecta as deficiências dos fatores VIII, IX, XI e XII, pré-calicreína e cininogênio de alto peso molecular. É usado como teste de triagem para deficiências de fator, presença de inibidores e para monitorizar o uso de heparina não fracionada.

Quando uma mistura de plasma e fosfolipídeo (substituto da plaqueta) é recalcificada, a fibrina é formada a uma velocidade normal que depende dos 
fatores envolvidos na via intrínseca (pré-calicreína, cininogênio de alto peso molecular, fatores VIII, IX, XI, XII) e na via comum (fatores X e V, protrombina e fibrinogênio). O TTPa é realizado por adição de tromboplastina parcial e cefalina, um ativador da via intrínseca. O cloreto de cálcio é adicionado e o tempo necessário para formar coágulo é medido.

A tromboplastina parcial utilizada no TTPa é incapaz de ativar a via extrínseca, que requer tromboplastina completa, isto é, o fator tecidual. Por consequência, este teste sobrepuja a via extrínseca, não sendo afetado pela deficiência do fator VII.

Um TTPa prolongado com um TP normal indica uma possível deficiência de fatores VIII, IX, XI, XII, cininogênio de alto peso molecular, pré-calicreína ou a presença de inibidor da via intrínseca. Nesses casos, uma mistura de plasma normal e plasma teste deverá ser feita. Caso haja correção de mais de $50 \%$ da diferença existente entre os tempos de coagulação do plasma-teste e da mistura, sugere-se a deficiência de um fator. Caso contrário, a ausência de correção sugere a presença de inibidor de um dos fatores de coagulação ou presença de anticoagulante lúpico (29).

\subsubsection{Tempo de trombina (TT)}

O TT avalia o tempo de coagulação do plasma citratado na presença de trombina, permitindo testar a conversão de fibrinogênio a fibrina. 
A trombina é adicionada ao plasma-teste para determinar o tempo de formação do coágulo. O tempo de coagulação, após a adição de trombina ao plasma, é inversamente proporcional à concentração de fibrinogênio presente.

O TT avalia diretamente o fibrinogênio funcional, sendo utilizado para investigar defeitos na molécula do fibrinogênio. Está prolongado na presença de heparina, em altas concentrações de imunoglobulinas (por exemplo, na macroglobulinemia de Waldenstrom), nas disfibrinogenemias, na hipofibrinogenemia e incoagulável na afibrinogenemia.

O TT é um teste de alta sensibilidade à presença de heparina, sendo utilizado para detecção de heparina não fracionada contaminante de amostras colhidas de cateteres de longa permanência, mantidos com heparina. Nestes casos, o TT é incoagulável e o TTPA prolongado, devendo ser feita nova coleta (29).

\subsubsection{Fator de vonWillebrand (FvW)}

O FvW é uma proteína de adesão, sintetizado pelas células endoteliais e megacariócitos. Está presente no plasma, no subendotélio e nos grânulos alfa das plaquetas.

A primeira das três funções conhecidas do FvW na hemostasia é ligar-se às estruturas expostas do subendotélio e, consequentemente, às plaquetas através dos receptores plaquetários GPIb/IX/V. Essa interação inicia a hemostasia primária, principalmente em condições de alto fluxo vascular (alta força de cisalhamento). A segunda função é a ligação entre as plaquetas 
(agregação plaquetária) através dos receptores GPIlb/IIla plaquetários, também em condições de alta força de cisalhamento. Além disso, o FvW participa da hemostasia secundária, transportando o fator VIII na circulação, que, quando livre, é rapidamente inativado. Desta forma, a dosagem do fator VIII poderá, de forma grosseira, mostrar indiretamente os níveis de FvW (29).

\subsubsection{D-dímero}

O D-dímero é um produto específico da degradação de fibrina (30). Assim, a presença de D-dímero no plasma indica formação de trombo. Entretanto, existem outras situações em que há aumento dos níveis de Ddímero não relacionados à formação de trombo (Tabela 3).

Existem 3 métodos de ensaios para a determinação do D-dímero:

- ELISA: método quantitativo e sensível

- Látex: semiquantitativo e menos sensível que ELISA

- Látex automatizado com leitura imunoturbidimétrica: quantitativo e sensibilidade semelhante a ELISA

Tabela 3: Situações em que o D-dímero pode estar aumentado

\begin{tabular}{l|l}
\hline Acidente vascular cerebral (AVC) & Período neonatal \\
\hline Gravidez & Infecção \\
\hline Tumor & Trauma, queimadura \\
\hline Coagulação intravascular & Tromboembolismo venoso \\
disseminada & \\
\hline
\end{tabular}




\begin{tabular}{l|l}
\hline Cardiopatia isquêmica & Hemólise (anemia falciforme) \\
\hline Doença renal ou hepática & Doença inflamatória intestinal \\
\hline Terapia trombolítica & Insuficiência cardíaca \\
\hline
\end{tabular}

\subsubsection{Função plaquetária}

As plaquetas são fragmentos citoplasmáticos anucleados derivados de megacariócitos. Circulam na periferia do vaso na forma discóide. Quando ativadas, emitem pseudópodes e mudam para a forma esférica. No sangue periférico, o número dessas células pode variar de 150.000 a $450.000 / \mathrm{mm}^{3}$.

No mecanismo hemostático, as plaquetas participam tanto da hemostasia primária (adesão, agregação e secreção) quanto da hemostasia secundária, fornecendo fosfolípides de membrana para o ancoramento e ativação dos fatores de coagulação (29).

\subsubsection{Adesão plaquetária}

Quando o vaso é lesado, ocorre exposição dos componentes subendoteliais (colágeno, fibronectina e laminina). O FvW circulante facilita a adesão inicial se ligando ao complexo plaquetário GPIb/IX/V, em condições de alta força de cisalhamento. Essa interação favorece outras ligações ao colágeno subendotelial através dos receptores GPla/lla e GPVI que também promovem a ativação plaquetária. 


\subsubsection{Agregação plaquetária}

A resposta da ativação plaquetária inclui mudanças da forma, com emissão de pseudópodes e exposição de fosfolípides de carga negativa na superfície plaquetária, facilitando a interação com as proteínas da coagulação. Além disso, há exposição do sítio ligante do complexo GPIIb/Illa ao fibrinogênio e a interação plaqueta-fibrinogênio-plaqueta e plaqueta-FvW-plaqueta, resultando na agregação plaquetária.

\subsubsection{Secreção plaquetária}

Durante o processo de ativação, o conteúdo dos grânulos alfa, densos e lisossomais plaquetários é secretado, amplificando o recrutamento e ativação de outras plaquetas circulantes para o local próximo a lesão. A partir dos grânulos alfa, são liberados FvW, fatores de coagulação, tais como, fibrinogênio, fator V/XI/XIII, proteína de adesão P-selectina, fator plaquetário, inibidor de plasminogênio, vitronectina e trombospondina. A partir dos grânulos densos, são liberados ADP, ATP e íons de cálcio. Enquanto pelos lisossomos,

são liberados as glicosidades e proteases que são enzimas críticas para a função plaquetária. Concomitantemente, é liberado o ácido araquidônico ligado à fosfatidilcolina da membrana plaquetária por ação da fosfolipase $A_{2}$. O ácido araquidônico livre é metabolizado pela enzima ciclo-oxigenase (COX), tendo como produto o tromboxano $\mathrm{A}_{2}$, potente agente agregante e quimiotático para outras plaquetas e leucócitos. 


\subsubsection{Outros processos bioquímicos envolvidos na agregação e} secreção plaquetária

O ADP liberado, a trombina gerada no início da cascata da coagulação, o colágeno e tromboxano $A_{2}$ se ligam a receptores transmembranas específicos das plaquetas circulantes. O sinal de ativação para o interior da célula é transmitida pelas proteínas G, que ativam outras enzimas, levando a mudança no citoesqueleto, favorecendo a emissão de pseudópodes e exposição da membrana pró-coagulante e do complexo GPIIb/IIla.

Alterações na função plaquetária ou do número de plaquetas causam desequilíbrio nas fases iniciais do sistema hemostático, resultando em manifestações hemorrágicas ou trombóticas.

\subsubsection{Avaliação da função plaquetária}

A função plaquetária será determinada através do uso do "Diamed Impact-R Teste Kit” (Figura 3). 


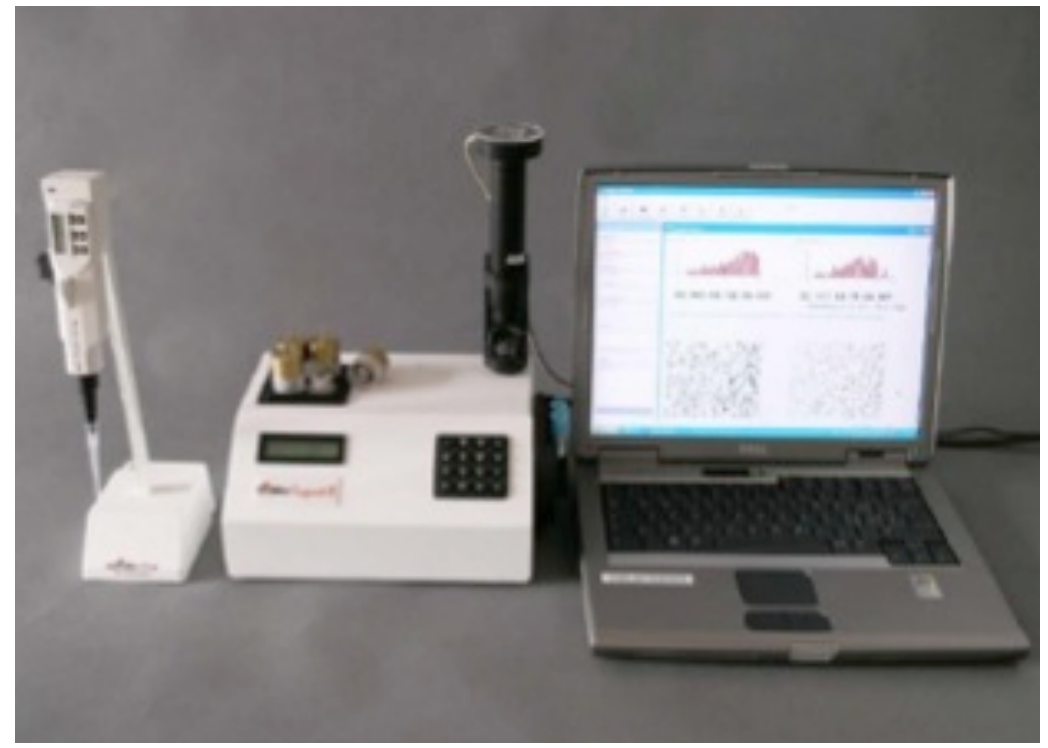

Figura 3: Equipamento utilizado para avaliação da função plaquetária

O equipamento "Diamed Impact-R" testa a função plaquetária (hipofunção plaquetária, hiperfunção plaquetária ou normal) em amostras de sangue total anticoagulado, sob condições de fluxo arterial $(720 \mathrm{rpm}$, por 2 minutos). O fluxo laminar sobre a superfície de poliestireno do poço é alcançado de acordo com o princípio de Cone e Placa. A amostra de sangue (130 $\mu \mathrm{L}$ ) aplicada no poço de poliestireno, as proteínas plasmáticas imediatamente aderem à superfície do poço e atraem as plaquetas, resultando na adesão e agregação plaquetária na superfície do poço em uma situação que simula o fluxo sanguíneo, de acordo com o princípio do Cone e Placa (Figura 4). Após essa etapa, o excesso de sangue é removido e o poço é corado por 1 minuto com solução azul de metileno de May-Grunwald. O excesso de corante é removido. Assim que a placa estiver seca, é realizada a captação de 7 imagens da placa e o resultado é calculado pelo programa de computador (31). 

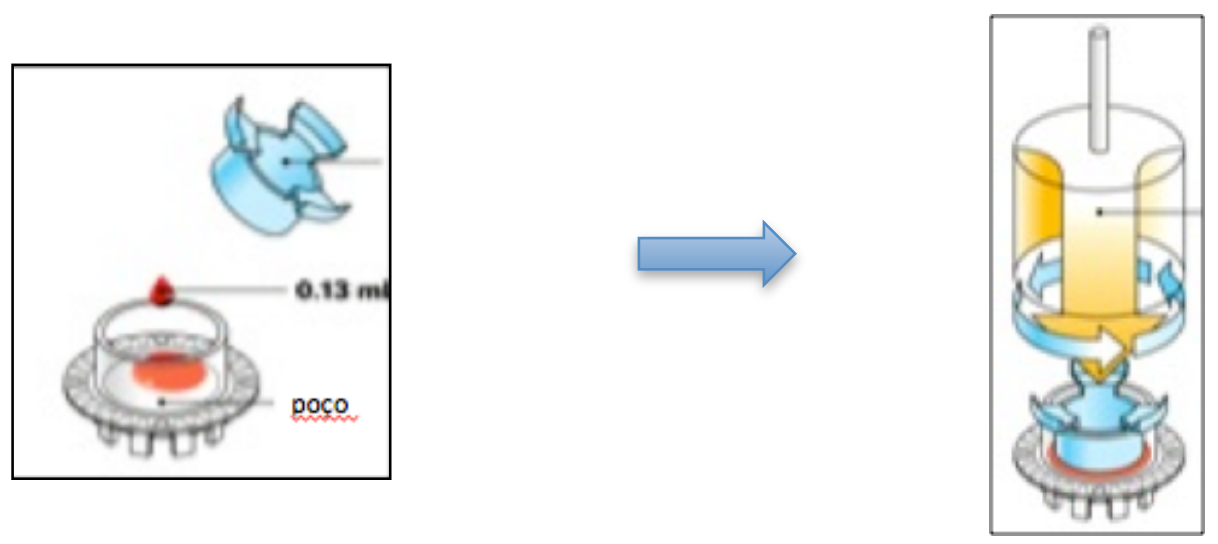

Figura 4. Avaliação da função plaquetária: princípio do cone e placa.

Os parâmetros e resultados fornecidos pelo equipamento devem ser interpretados conforme a Tabela 4.

Tabela 4. Impact-R: parâmetros e interpretação

\begin{tabular}{l|l}
\hline \multicolumn{1}{c|}{ Parâmetro } & \multicolumn{1}{c}{ Interpretação } \\
\hline SC (surface covered, superfície coberta) & $\begin{array}{l}\text { Porcentagem da superfície coberta } \\
\text { por agregados plaquetários, } \\
\text { representando adesão plaquetária }\end{array}$ \\
\hline AS (average size, tamanho médio) & Tamanho médio dos agregados, \\
& representando agregação \\
& plaquetária \\
\hline
\end{tabular}




\subsubsection{Tromboelastografia}

Atualmente, ainda não existe um único exame laboratorial que permite mostrar globalmente toda a cinética da hemostasia in vivo. Os testes de coagulação convencionais geralmente avaliam uma parte isolada do sistema de coagulação.

O sistema de coagulação, na concepção atual, pode ser dividido em duas fases: a iniciação e a propagação. Durante a iniciação, o fator tecidual é exposto e forma um complexo com o fator VII ativado (FVIla), ativando o fator $\mathrm{X}$ $(F X)$, o que leva à produção de pequena quantidade de trombina. A trombina, por sua vez, inicia a polimerização do fibrinogênio em fibrina. Subsequentemente, a trombina ativa as plaquetas, o fator VIII (FVIII) e fator V $(\mathrm{FV})$, o que gera a alça de amplificação da fase de propagação, levando à produção de grandes quantidades de trombina e do complexo fibrina-plaqueta.

Análises tradicionais da coagulação, tais como o TP e TTPa, são realizadas em plasma pobre em plaquetas. Assim, elas fornecem apenas informações relacionadas às fases iniciais da coagulação e falham no fornecimento de informações relacionadas à fase de propagação da formação de coágulos. A tromboelastografia (TEG), entretanto, fornece o perfil global da coagulação continuamente desde o início da formação de coágulo até a fibrinólise. As informações que podem ser obtidas através da TEG incluem a qualidade do coágulo até a dinâmica da sua formação (32) .

A tromboelastografia foi primeiramente descrita por Hartert em 1948 (33). Na TEG, as alterações viscoelásticas que ocorrem na coagulação são 
gravadas, gerando uma representação gráfica do processo de polimerização da fibrina. Desta forma, o tromboelastógrafo $\left(\mathrm{TEG}^{\circledR}\right.$; Haemoscope Corporation, IL, USA) permite uma avaliação completa do processo de iniciação, formação e estabilidade do coágulo, utilizando-se sangue ou plasma.

$O$ traçado do $\mathrm{TEG}^{\circledR}$ pode revelar situações hipocoagulantes ou hipercoagulantes. Pode ser utilizada inclusive para avaliar hemostasia secundária. Pacientes com discreta deficiência de fatores de coagulação podem apresentar TP e TTPa normais, porém com traçados do TEG alterados.

$O T E G^{\circledR}$ é útil em situações complexas. Seu principal uso tem sido para monitorar a necessidade de transfusão durante cirurgias. A primeira utilização foi descrita no transplante de fígado em 1985 por Kang e cols.(ref). O uso em cirurgia cardíaca foi descrito posteriormente em 1999 por Shore-Lesserson e cols. (ref). Cirurgias de fígado e cardíacas estão associadas a potencial perda maciça de sangue e consequente alteração da hemostasia. Em pacientes de trauma, $\mathrm{TEG}^{\circledR}$ pode predizer a necessidade de transfusão precoce.

A avaliação da hipercoagulabilidade é outra indicação da TEG, que neste caso, mostra um traçado específico. O estado de hipercoagulabilidade pode ser encontrado em pacientes em uso de anticoncepcionais, obesidade, período pós-operatório, uremia, trauma e câncer.

A vantagem da TEG está na capacidade de fornecer rapidamente a representação da função plaquetária, das proteases e inibidores da coagulação e do sistema fibrinolítico. Os resultados do teste permitem analisar a necessidade de transfusão sanguínea e o melhor manejo no uso de 
anticoagulantes. Atualmente, nos laboratórios, a tecnologia tem sido usada nas áreas em que exames convencionais de coagulação são inadequados. Essas áreas compreendem o rastreamento de hipercoagulabilidade, o estudo de estados pró-trombóticos e nos pacientes com hemofilia para monitorar o tratamento (34).

\subsubsection{Princípios do TEG ${ }^{\circledR}$}

$\mathrm{O} T E \mathrm{G}^{\circledR}$ fornece uma representação gráfica da formação de coágulo e subsequente lise (Figuras 5 e 6 ). $\mathrm{O}$ sangue é incubado a $37^{\circ} \mathrm{C}$ em um copo aquecido. Dentro do copo, é suspenso um pino conectado a um detector. Nesse sistema, o copo oscila em um ângulo de $4^{\circ} 45^{\prime}$. Cada ciclo de rotação dura 10 segundos (Figura 7). A partir do momento em que houver formação de fibrina-plaqueta, há uma força tensional que é transmitida ao pino. Assim, quanto mais firme for o coágulo, maior será a força transmitida ao pino. Da mesma forma, quando houver a retração do coágulo ou lise, essa força tensional sobre o pino diminui. A força tensional exercida no pino é convertida em sinal elétrico, o que pode ser visualizado no computador através de programa específico do aparelho (35).

O aparelho ROTEM (tromboelastometria rotacional) é uma adaptação do $\mathrm{TEG}^{\circledR}$. Nesse caso, o copo fica estático e o pino faz movimento de rotação diretamente na amostra. Os resultados são idênticos ao TEG ${ }^{\circledR}$. 


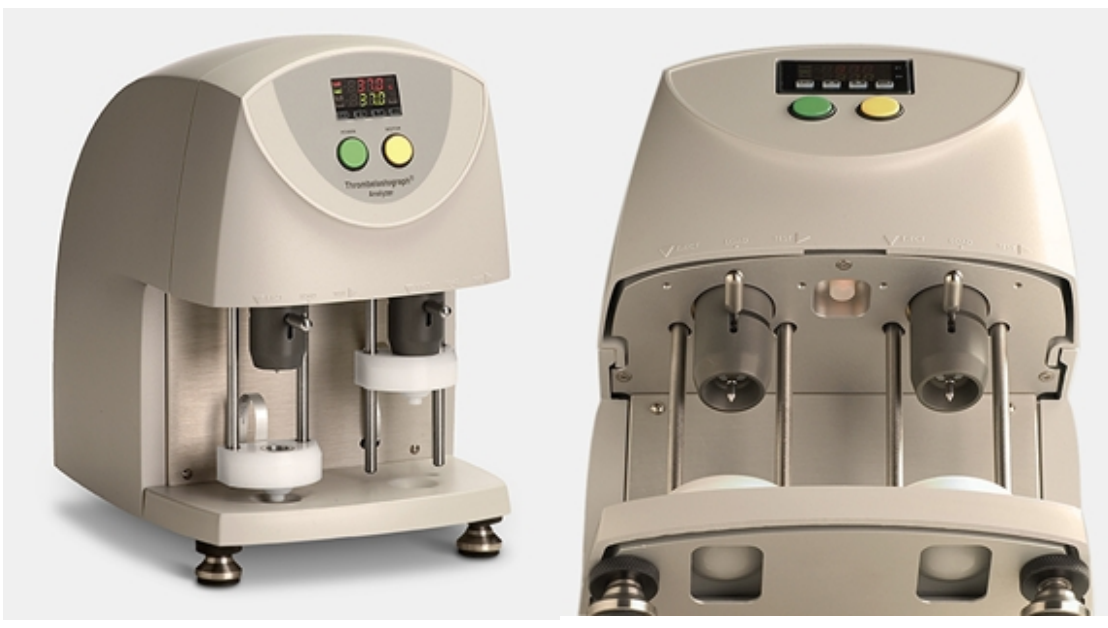

Figura 5. TEG ${ }^{\circledR}$

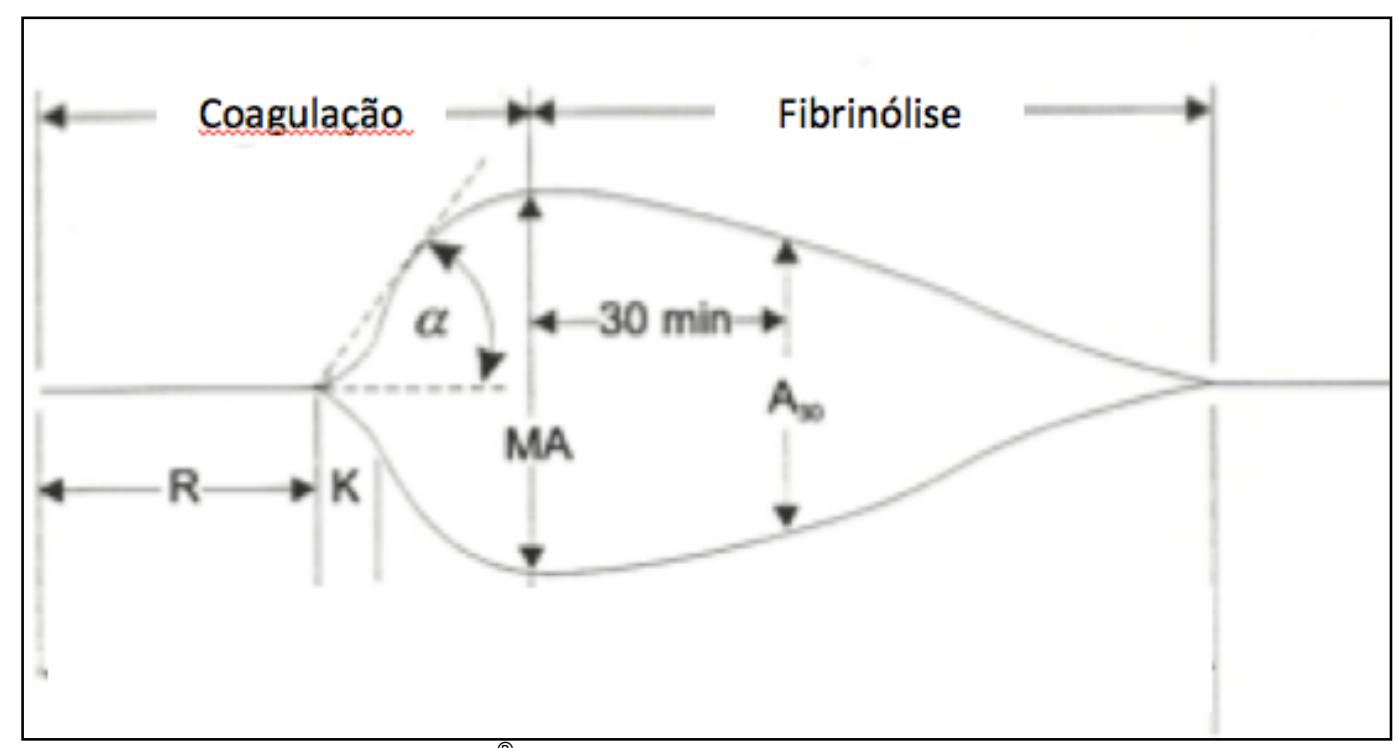

Adaptado de Thromboelastograph ${ }^{\circledR}$ Haemostasis Analyser, user's manual

Figura 6. Representação gráfica da coagulação 


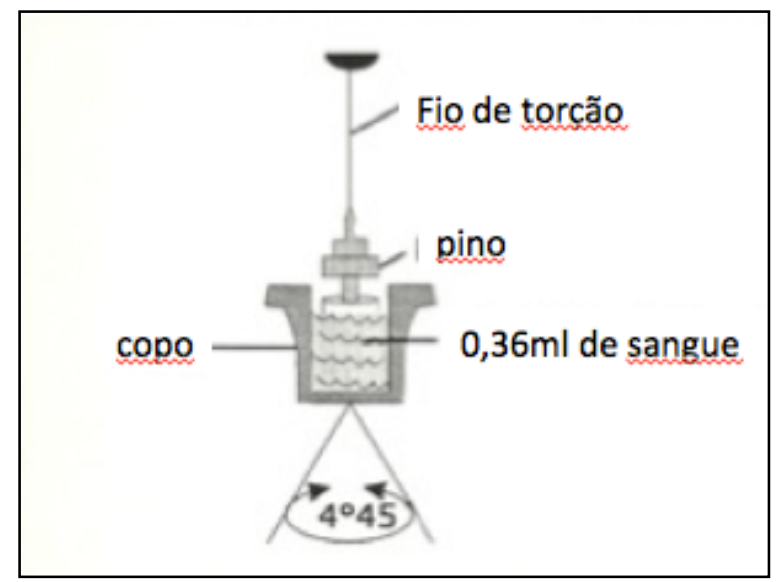

Adaptado de Thromboelastograph ${ }^{\circledR}$ Haemostasis Analyser, user's manual

Figura 7. Mecanismo da tromboelastografia.

\subsubsection{Análise quantitativa dos parâmetros do TEG ${ }^{\circledR}$}

Para avaliar a informação gráfica disponibilizada, cinco parâmetros relacionados à formação de coágulo e lise são analisados: R, K, a, MA, LY30. Os parâmetros e suas respectivas interpretações estão resumidos na Tabela 5. 
Tabela 5: Interpretação dos resultados do TEG ${ }^{\circledR}$

\begin{tabular}{l|l}
\hline \multicolumn{1}{c|}{ Parâmetro } & \multicolumn{1}{c}{ Interpretação } \\
\hline R (tempo de reação) & $\begin{array}{l}\text { Tempo entre a colocação da amostra de sangue no } \\
\text { analisador até a formação inicial de fibrina }\end{array}$ \\
\hline K (tempo K) & $\begin{array}{l}\text { Tempo entre o início da formação de fibrina até } \\
\text { certo nível de firmeza do coágulo (amplitude de 20 }\end{array}$ \\
\hline m (ângulo) & $\begin{array}{l}\text { Mede a rapidez da formação de fibrina e firmeza do } \\
\text { coágulo (clot strengthening). Velocidade da geração } \\
\text { de trombina. }\end{array}$ \\
\hline MA (amplitude máxima) & $\begin{array}{l}\text { Fornece informações sobre a ligação da fibrina e } \\
\text { plaquetas via GPIlb/llla e representa a força do } \\
\text { coágulo de fibrina }\end{array}$ \\
\hline
\end{tabular}

$R$ (valor normal 5-10min) - tempo entre o início da análise da amostra até a detecção de coágulo (amplitude de $2 \mathrm{~mm}$ no traçado). Tempo R pode estar prolongado devido a anticoagulantes, hipofibrinogenemia ou deficiência de fatores e encurtado em situações de hipercoagulabilidade.

$\mathrm{K}$ (valor normal 1-3 min) - o tempo K é uma medida de velocidade ou cinética do coágulo para alcançar determinada força do coágulo. O tempo $\mathrm{K}$ está 
diminuído quando o nível de fibrinogênio está elevado ou, em menor proporção, quando há hiperfuncionamento plaquetário e prolongado quando há uso de anticoagulantes, hipofibrinogenemia, deficiência de fatores de coagulação.

a (valor normal $45-74^{\circ}$ ) - cinética do desenvolvimento do coágulo. O ângulo está relacionado ao tempo $\mathrm{K}$, ambos indicam a razão de polimerização. $\mathrm{O}$ ângulo é mais abrangente do que o tempo K, uma vez que existe situação hipocoagulante quando a firmeza do coágulo não atinge a amplitude de $20 \mathrm{~mm}$ (neste caso, o tempo $\mathrm{K}$ é indefinido). O ângulo está aumentado quando o nível de fibrinogênio está elevado ou, em menor proporção, quando há hiperfuncionamento plaquetário e reduzido quando há deficiência dos fatores de coagulação, hipofibrinogenemia, plaquetopenia e disfunção plaquetária.

MA (valor normal 54-62mm) - medida da força máxima do coágulo. A força do coágulo depende de 2 componentes: a contribuição da fibrina, e principalmente, das plaquetas. Está reduzida em situações de hipofibrinogenemia, plaquetopenia e disfunção plaquetária.

$\mathrm{Cl}$ (índice de coagulação; valor normal $-3 \mathrm{a}+3$ ) - descreve a coagulação global do paciente, utilizando os parâmetros $R, K$, ângulo e MA.

\subsubsection{Análise qualitativa dos parâmetros do TEG ${ }^{\circledR}$}

O traçado do $\mathrm{TEG}^{\circledR}$ também pode ser qualitativamente analisado. Os padrões são facilmente interpretados (Figuras 8, 9, 10, 11), sem medição, para 
determinar condições hipercoagulantes, hipocoagulantes ou normocoagulantes (35).

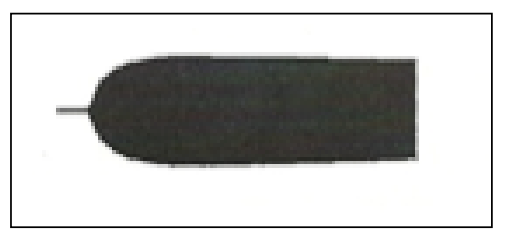

Figura 8: Traçado normal

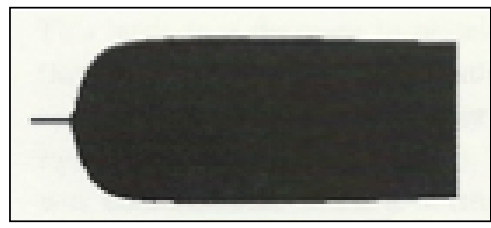

Figura 9: Hipercoagulante (R e K diminuídos; MA e ângulo aumentados)

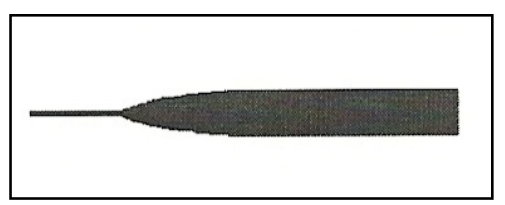

Figura 10: Hipocoagulante (R prolongado; K, ângulo e MA diminuídos)

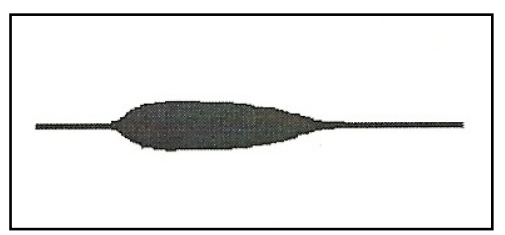

Figura 11: Fibrinólise (R normal; K, ângulo e MA reduzidos; MA decrescente) 


\subsubsection{Teste da geração de trombina}

A primeira etapa que sucede imediatamente à lesão tecidual no organismo é a rápida vasoconstrição dos vasos sanguíneos. A segunda etapa consiste na formação de coágulo plaquetário via interação do fator de vonWillebrand e plaquetas. A terceira etapa consiste na aceleração da via extrínseca da coagulação.

A liberação de fator tecidual (TF) resulta na formação de trombina, que ativa o fibrinogênio em fibrina, levando à polimerização da fibrina e formação de coágulo de fibrina. Assim, pode-se notar que a trombina é um fator regulador importante deste processo de coagulação.

O Trombograma Automatizado Calibrado (Figura 12) desenvolvido pela Thrombinoscope/Diagnosica Stago, permite a mensuração da atividade da trombina. O teste consiste em colocar em uma placa com 96 poços, amostras de plasmas a serem analisadas. Em seguida, fator tecidual e calibrador são adicionados. O calibrador permite a correção da variação da coloração, turbidez ou hemólise das amostras de provenientes de diversos pacientes. 


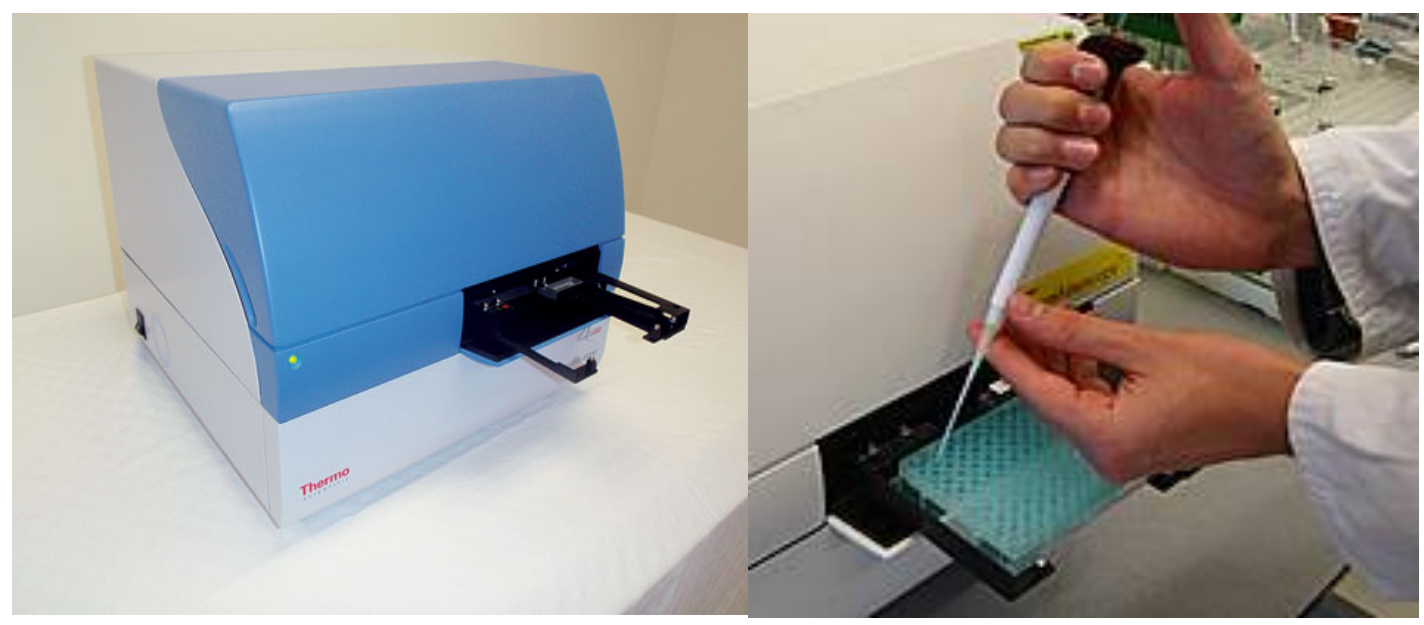

Figura 12: Aparelho para análise da geração de trombina.

Após o preenchimento da placa com as amostras a serem analisadas, ela é colocada no aparelho Thermo Fluoroskan Ascent. Um dispensador dentro do aparelho adiciona uma mistura de substrato/cálcio fluorogênico em cada poço, ativando a coagulação. A seguir, a amostra é analisada e lida em 60 minutos. Um programa de computador específico do aparelho, então, calcula os parâmetros da curva adquirida (Figura 13). Os parâmetros fornecidos são: lag time, pico, tempo para o pico (time to peak), área sob a curva (area under the curve; também conhecido como potencial endógeno de trombina - ETP) (34).
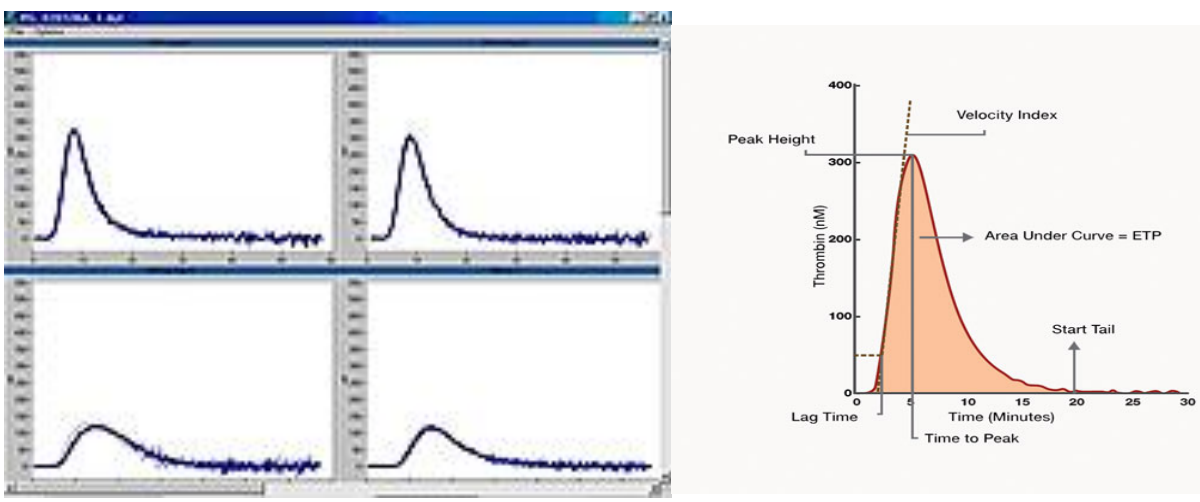

Figura 13: Curva para análise da geração de trombina 


\subsection{Pacientes oncológicos e injúria renal aguda}

A população mundial está envelhecendo. Sabe-se que comorbidades crônicas são mais prevalentes em idosos, tais como: hipertensão, diabetes, doenças cardiovasculares, insuficiência renal e câncer. Cerca de 60\% dos casos de câncer ocorrem em pessoas acima de 65 anos de idade. Nos últimos 20 anos, o tratamento do paciente oncológico mudou dramaticamente com a introdução de novos protocolos de terapias e melhoria nos cuidados de terapia intensiva. Com isso, houve progresso no prognóstico e sobrevida dos pacientes, mas também trouxe um maior número de complicações clínicas que requerem cuidados intensivos em ambiente de terapia intensiva $(37,38)$.

Os pacientes oncológicos são pacientes de risco para desenvolver injúria renal aguda (IRA), termo utilizado para o declínio súbito da função renal, ocasionando distúrbios hídricos, eletrolíticos e acidose devido à redução do ritmo de filtração glomerular (RFG) (39). A IRA é uma complicação comum nesses pacientes e pode ocorrer como consequência do próprio câncer (nefropatia cilíndrica, obstrução renal), do tratamento (lise tumoral, nefropatia induzida por drogas, procedimentos cirúrgicos) ou associado a complicações severas tais como, a sepse. Além disso, a disfunção renal está relacionada com pior prognóstico e pode ser um fator limitante para instituir terapias anticancerígenas (40).

A IRA é encontrada em $36 \%$ a $67 \%$ dos pacientes em UTI, dependendo da definição de IRA utilizada, e associada com aumento da morbidade e mortalidade. Em vários estudos, foi demonstrado que a mortalidade aumenta proporcionalmente com a gravidade da IRA. Aqueles que necessitam de 
diálise, a mortalidade pode chegar a $70 \%$ (39). Em pacientes críticos com câncer, a IRA ocorre geralmente no contexto de disfunção de múltiplos órgãos e está associada à mortalidade de $53 \%$ a $93 \%$ (40). Além do impacto na mortalidade, a IRA resulta em um maior custo da internação hospitalar, maior tempo de permanência hospitalar e maior chance de evoluir para doença renal crônica (39).

\subsubsection{Classificação da injúria renal aguda}

Existem na literatura mais de 35 definições de IRA (41). Com o objetivo de padronizar a definição e classificação da IRA e facilitar a comparação entre os diversos estudos, foi proposta uma classificação pelo Acute Kidney Injury Network (AKIN). No critério proposto pelo AKIN, a IRA é definida por uma perda abrupta (dentro de 48 horas) da função renal, caracterizada por um aumento absoluto da creatinina sérica maior ou igual a $0,3 \mathrm{mg} / \mathrm{dL}$ ou um aumento percentual da creatinina sérica maior ou igual a 50\% (aumento de 1.5 vezes em relação ao valor de base) ou redução do débito urinário para menos de $0.5 \mathrm{ml} / \mathrm{kg}$ por hora por mais de 6 horas (40). Além disso, o AKIN ainda classifica a IRA em 3 estágios, baseando-se nos valores de creatinina sérica e débito urinário.

- Estágio 1: aumento da creatinina sérica $\geq 0.3 \mathrm{mg} / \mathrm{dL}$ ou aumento de 150 - 200\% em relação à creatinina de base (aumento de 1.5 2 vezes) ou diurese $<0.5 \mathrm{ml} / \mathrm{kg} / \mathrm{h}$ por mais de 6 horas

- Estágio 2: aumento da creatinina sérica de 200 - 300\% em relação à creatinina de base (aumento de 2 - 3 vezes) ou diurese $<0.5 \mathrm{ml} / \mathrm{kg} / \mathrm{h}$ por mais de 12 horas 
- Estágio 3: aumento da creatinina sérica $\geq 300 \%$ ( aumento maior que 3 vezes) em relação à creatinina de base ou aumento da creatinina $\geq 0.5 \mathrm{mg} / \mathrm{dL}$ naqueles com creatinina $\geq 4 \mathrm{mg} / \mathrm{dL}$ ou diurese $<0.3 \mathrm{mg} / \mathrm{dL} / \mathrm{h}$ por 24 horas ou anúria por 12 horas.

Diversos estudos têm demonstrado aumento da mortalidade em pacientes clínicos e cirúrgicos com IRA classificada pelo AKIN, bem como uma morbimortalidade crescente, de acordo com a progressão nos estágios do $\operatorname{AKIN}(42,43)$.

Chertow e cols. mostraram em recentes estudos epidemiológicos que pequenos aumentos nos níveis de creatinina $(0,3 \mathrm{mg} / \mathrm{dL})$ em pacientes hospitalizados, já levam ao aumento importante do risco de mortalidade (44). A importância desse resultado foi confirmada em um estudo por Barri e cols, onde se mostrou que pacientes submetidos a transplante hepático e que desenvolveram IRA, mesmo com pequenos aumentos de creatinina $(0,5$ $\mathrm{mg} / \mathrm{dL}$ ), estavam associados com menor sobrevida do enxerto e do paciente (44) .

\subsubsection{Uremia e sangramento}

O sangramento ocasionado pela uremia é uma complicação descrita nos pacientes com falência da função renal (45).

É bem conhecido, há décadas, que o sangramento decorrente da uremia e da disfunção plaquetária coloca os pacientes em risco de sangramento generalizado (46). O mecanismo exato para esse sangramento ainda não está 
bem elucidado, mas parece ser multifatorial. Paradoxalmente, apesar da redução da função plaquetária, esses pacientes apresentam uma alta prevalência de complicações cardiovasculares e trombóticas.

O primeiro e importante fator que contribui para o sangramento na uremia é a disfunção do fator de Von Willebrand (FvW). Essa molécula de adesão é reconhecida pelos receptores GPlb/IX. A ligação FvW a esses receptores inicia uma série de reações bioquímicas intracelulares, resultando na produção de tromboxane $A_{2}$. A interação entre FvW e GPIb/IX facilita a ativação do receptor GPIv/IIla, que permite a agregação plaquetária. Nos pacientes urêmicos com disfunção plaquetária, há defeito funcional no FvW devido à redução da afinidade de ligação com o receptor GPIb/IX ou da expressão reduzida dos receptores de GPIb/IX plaquetários. A fraca interação entre FvW e receptor GPIb/IX resulta na redução da produção de tromboxane $A_{2}$ e ADP. Há também redução da função do fator VIII, que é normalmente transportado no sangue pelo FvW (47).

Pacientes com coagulopatia secundária à disfunção renal apresentam níveis mais elevados de prostaciclina $\left(\mathrm{PGI}_{2}\right)$, um vasodilatador e inibidor de agregação plaquetária (48).

Pacientes com redução da função renal retém aproximadamente 92 tipos de solutos urêmicos, conhecidos como toxinas urêmicas. O acúmulo dessas toxinas interfere no funcionamento biológico e bioquímico do organismo, incluindo a função plaquetária (49). A diálise melhora a disfunção plaquetária e reduz o risco de hemorragia. Entretanto, a diálise pode até 
contribuir para o sangramento devido à ativação plaquetária induzida pela interação entre o sangue e superfície artificial do circuito da diálise.

A anemia é comumente encontrada nos pacientes com insuficiência renal crônica devido à redução da produção de eritropoetina e da diminuição da vida útil das hemácias. A diminuição do número de hemácias circulantes faz com que as plaquetas percorram mais pela região central dos vasos sanguíneos, reduzindo a interação com o endotélio. As hemácias também liberam $A D P$ e tromboxane $A_{2}$, portanto, uma diminuição da quantidade de hemácias resulta na diminuição da agregação plaquetária (47). 


\section{OBJETIVOS}

1. Avaliar o perfil de coagulação dos pacientes oncológicos com sepse grave ou choque séptico admitidos na UTI

2. Avaliar o efeito da IRA na coagulação e perfil de hemostasia destes pacientes oncológicos. 


\section{MÉTODOS}

O protocolo de pesquisa e o Termo de Consentimento Livre e Esclarecido (TCLE) foram submetidos à comissão científica do Instituto do Câncer do Estado de São Paulo (ICESP) e ao Comitê de Ética em Pesquisa (CEP) da Faculdade de Medicina da Universidade de São Paulo.

Foram estudados pacientes oncológicos admitidos nas Unidades de Terapia Intensiva (UTI) do Instituto do Câncer do Estado de São Paulo no período de julho de 2012 a janeiro de 2014, com diagnóstico de sepse grave ou choque séptico.

\subsection{Avaliação do sistema de coagulação}

O perfil de coagulação estudado compreendeu: TP, TTPa, TT, D-dímero, fibrinogênio, fator VIII, avaliação de adesão e agregação plaquetária com Impact-R, tromboelastografia (para avaliar o perfil completo da coagulação) e avaliação da geração de trombina. Dados clínicos e epidemiológicos foram obtidos a partir de prontuários.

Diferentemente do que ocorre atualmente na prática clínica, onde somente algumas etapas da cascata da coagulação são avaliadas, neste projeto, incluiuse a tromboelastografia e a geração de trombina, os quais forneceram informações globais e detalhadas de toda a cascata da coagulação. 
As informações clínicas foram armazenadas em um banco de dados (planilha em Microsoft Office Excel) desenvolvido para a análise estatística das informações obtidas.

\subsection{Tempos de coleta de amostras de sangue}

A coleta de exames de sangue foi realizada nos seguintes tempos, de acordo com a evolução clínica dos pacientes:

1. A primeira amostra no momento da admissão na UTI de todos os pacientes que preencheram os critérios de inclusão

2. Se nas primeiras 48 horas, o paciente evoluiu para IRA-AKIN 1, houve a coleta da segunda amostra de exames. Se progrediu para AKIN 2, houve a coleta da terceira amostra. E se progrediu para AKIN 3, houve a coleta da quarta amostra.

3. Se nas primeiras 48 horas, o paciente evoluiu diretamente para AKIN 2, houve a coleta da segunda amostra de exames. E se progrediu para AKIN 3, houve a coleta da terceira amostra.

4. Se nas primeiras 48 horas, o paciente evoluiu diretamente para AKIN 3, houve a coleta apenas da segunda amostra.

5. Se o paciente não evoluiu com IRA nas primeiras 48 horas, houve a coleta de uma segunda amostra neste período. 


\subsection{Coleta e análise das amostras de sangue}

Foi realizada a coleta de $20 \mathrm{~mL}$ de sangue nos pacientes que preencheram os critérios de inclusão/exclusão. O sangue foi coletado em tubos a vácuo contendo citrato de sódio a 3.2\% (Labor Import,Shandong Weigao Group Medical Polymer Co Ltd, RPC). A seguir, o material foi enviado para o laboratório de coagulação do Serviço de Hematologia do HCFMUSP, onde foi processado e analisado.

O sangue total foi utilizado para a avaliação da adesão e agregação plaquetária pelo Impact-R e a realização de tromboelastografia.

A tromboelastografia foi realizada no aparelho Thrombelastograph ${ }^{\circledR}$ Hemostasis Analyzer da marca Haemoscope, de acordo com as técnicas fornecidas pelo fabricante.

A adesão e agregação plaquetária foi analisada no aparelho Impact-R da marca DiaMed, de acordo com as técnicas fornecidas pelo fabricante.

Para a avaliação de TP, TTPa, TT, D-dímero, fibrinogênio, fator VIII foi utilizado plasma obtido através da centrifugação dos tubos coletados por 15 minutos a 3.000 rpm na centrífuga (Eppendorf Centrifugue 5804R).

O TP foi medido de acordo com a técnica de Quick modificada (50), utilizando-se o reagente PT-fibrinogen HS PLUS (Instrumentation Laboratory, USA) no equipamento automatizado ACL TOP 500, da marca IL. 
O TTPa foi mensurado de acordo com a técnica Proctor \& Rapaport modificado (51), utilizando-se o reagente APTT-SP (Instrumentation Laboratory, USA) no equipamento automatizado ACL TOP 500, da marca IL.

O TT foi realizado de acordo com a técnica de Jim modificada (52), utilizando-se o reagente Thrombin Time (Instrumentation Laboratory, USA) no equipamento automatizado ACL TOP 500, da marca IL.

O D-dímero foi determinado de acordo com a técnica imunoensaio quantitativo automatizado por partícula de látex, utilizando-se o reagente apropriado (D-Dimer HemosIL, Instrumentation Laboratory, USA) no equipamento automatizado ACL TOP 500, da marca IL.

O fibrinogênio foi medido de acordo com a técnica Clauss modificada, utilizando-se o reagente Fibrinogen C-XL (Instrumentation Laboratory, USA) no equipamento automatizado ACL TOP 500, da marca IL.

$\mathrm{O}$ fator VIII foi determinado, utilizando-se o reagente Factor VIII deficient Plasma kit (Instrumentation Laboratory, USA) no equipamento automatizado ACL TOP 500, da marca IL.

Para a avaliação da geração de trombina, o plasma pobre em plaquetas obtido através da primeira centrifugação foi centrifugado novamente por 10 minutos a $10.000 \mathrm{~g}$ e prontamente congelado em nitrogênio líquido e estocado a $-80^{\circ} \mathrm{C}$ para posterior análise. No momento da análise, as amostras foram descongeladas em banho-maria a $37^{\circ} \mathrm{C}$ por 5 minutos. A dosagem foi realizada no aparelho Fluoroskan Ascent, da marca Thermo Scientific, de acordo com as técnicas fornecidas pelo manual do fabricante. 
Os kits utilizados para análise da geração de trombina são distribuídos pela Diagnostica Stago (França) e compreendem:

- FluCa-kit, Thrombinoscope, The Netherlands

- Thrombin Calibrator, Thrombinoscope, The Netherlands

- PPP-Reagent LOW, Thrombinoscope, The Netherlands

- PPP-Reagent, Thrombinoscope, The Netherlands

- PPP-Reagent HIGH, Thrombinoscope, The Netherlands

\subsection{Critérios de seleção dos pacientes}

\subsubsection{Critérios de inclusão}

Pacientes adultos, maiores de 18 anos, de ambos os sexos, portadores de tumor sólido ou hematológico, admitidos na UTI do ICESP com diagnóstico de sepse grave ou choque séptico foram considerados elegíveis.

\subsubsection{Critérios de exclusão}

- Pacientes menores de 18 anos de idade

- Pacientes com insuficiência renal crônica em programa regular de diálise

- Pacientes com doenças de coagulação sanguínea, através de dados de prontuário e história clínica (paciente com diagnóstico confirmado de coagulopatia ou história familiar de coagulopatia) 


\subsection{Cálculo do tamanho da amostra}

O cálculo do tamanho da amostra foi baseado nos resultados de pesquisas prévias realizadas na UTI do ICESP e nos dados da literatura médica.

Dados de pesquisas prévias realizadas na UTI do ICESP:

- São admitidos aproximadamente 40 pacientes por mês com diagnóstico de sepse grave ou choque séptico

- Em um estudo realizado, onde 119 pacientes foram estudados, a incidência de insuficiência renal aguda (IRA) foi de 50,4\%.

Foi realizada revisão da literatura e a seleção de trabalhos prévios que forneceram informações ao projeto:

- Perioperative hypercoagulability in uremic patients: a viscoelastic study (Journal of Clinical Anesthesia 9:442-445, 1997);

- D-dimer levels and risk of recurrent venous thromboembolism (JAMA, August 27, 2003, vol 290, No 8);

- Identification of patients at low risk for recurrent venous thromboembolism by measuring thrombin generation (JAMA, July 26 , 2006, vol 296, No 4);

- Comparison of thromboelastometry with procalcitonin, interleukin-6, and C-reactive protein as diagnostic tests for severe sepsis in critically ill adults (Critical Care 2010, 14:R178). 
Através dos dados obtidos e de cálculo estatístico através do programa da University of California, San Francisco (http://www.epibiostat.ucsf.edu/biostat/sampsize.html), calculou-se o tamanho da amostra, chegando-se ao número de 76 pacientes necessários em cada grupo (sepse grave/choque séptico com IRA x sepse grave/choque séptico sem IRA). O tamanho da amostra foi aumentado em $20 \%$ para eventuais perdas, totalizando-se 90 pacientes em cada grupo (total de 180 pacientes).

\subsection{Análise estatística}

As características quantitativas avaliadas foram descritas segundo grau de IRA (AKIN) com uso de medidas resumo (média, desvio padrão, mediana, $1^{\circ}$ quartil-Q1 e $3^{\circ}$ quartil-Q3) e comparadas entre os grupos com uso de testes Kruskal-Wallis ou ANOVA (Neter, et. al., 1996). Os testes foram seguidos de comparações múltiplas de Dunn (Neter, et. al., 1996) para verificar entre quais graus de IRA ocorreram as diferenças. As características qualitativas dos pacientes foram descritas segundo grau de IRA com uso de frequências absolutas e relativas, e verificada a existência de associação com grupo com uso de testes qui-quadrado ou testes da razão de verossimilhanças (Kirkwood e Sterne, 2006).

As características quantitativas foram descritas segundo óbito com uso de medidas resumo e comparadas segundo mortalidade com uso de testes Mann-Whitney ou teste t-Student (Kirkwood e Sterne, 2006). As características qualitativas foram descritas segundo mortalidade com uso de frequências 
absolutas e relativas, e verificada a existência de associação com uso de testes qui-quadrado ou testes exatos de Fisher. Foram estimados os Odds Ratio de cada variável de interesse com a mortalidade e os respectivos intervalos com 95\% de confiança através do uso de regressão logística bivariada (Hosmer e Lemeshow, 2000).

Foi estimado o modelo de regressão logística múltipla (Hosmer e Lemeshow, 2000) para verificar conjuntamente as variáveis que influenciam na mortalidade, selecionando-se as variáveis que nos testes bivariados apresentaram significância estatística $(p<0,05)$ e as variáveis que clinicamente podem influenciar na mortalidade. Foram mantidas no modelo final apenas as variáveis com nível de significância inferior a 0,05 $(p<0,05)$.

Os testes foram realizados com nível de significância de 5\%.

Os dados foram armazenados e analisados utilizando-se os programas SPSS (Statistical Package for the Social Sciences) versão 20.0 e Microsoft Office Excel 2003. 


\section{RESULTADOS}

Foram avaliados 170 pacientes na UTI do Instituto do Câncer do Estado de São Paulo da Faculdade de Medicina da Universidade de São Paulo (ICESP-FMUSP) no período de agosto de 2012 a janeiro de 2014. Destes, 14 foram excluídos por perda do material biológico; 3 eram menores de 18 anos; 5 eram portadores de insuficiência renal crônica dialítica e 4 apresentavam histórico de coagulopatia (TEP) em uso de anticoagulante. Sendo assim, foram incluídos no estudo 144 pacientes por terem preenchido todos os critérios de inclusão e exclusão.

$\mathrm{Na}$ Tabela 6, encontram-se os dados demográficos e clínicos dos pacientes envolvidos no estudo. Os grupos foram divididos conforme o grau máximo de AKIN atingido. 
TABELA 6. Dados demográficos e clínicos

\begin{tabular}{|c|c|c|c|c|c|c|}
\hline Variável & $\begin{array}{l}\text { Sem IRA } \\
(\mathrm{N}=46)\end{array}$ & $\begin{array}{c}\text { AKIN 1 } \\
(\mathrm{N}=34) \\
\end{array}$ & $\begin{array}{r}\text { AKIN 2 } \\
(\mathrm{N}=25) \\
\end{array}$ & $\begin{array}{c}\text { AKIN 3 } \\
(\mathrm{N}=39) \\
\end{array}$ & $\begin{array}{c}\text { Total } \\
(\mathrm{N}=144) \\
\end{array}$ & $\mathbf{p}$ \\
\hline Sexo (masculino), n (\%) & $25(54,3)$ & $20(58,8)$ & $=15(60)$ & $22(56,4)$ & $82(56,9)$ & 0.965 \\
\hline Idade (anos), média (DP) & $60,39(11,4)$ & $61,74(13,36)$ & $56,48(15,44)$ & $63,46(14,11)$ & $60,86(13,43)$ & $0,230^{* *}$ \\
\hline IMC (kg/m²), média (DP) & $24,06(5,26)$ & $22,93(4,12)$ & $22,09(4,48)$ & $23,17(6,15)$ & $23,24(5,15)$ & $0,540^{* *}$ \\
\hline Tempo na UTI (dias) & $5,5(2 ; 11)$ & $8(5 ; 9)$ & $6(6 ; 7)$ & $8,5(4 ; 10)$ & $7(3 ; 10)$ & $0,268 £$ \\
\hline Hipertensão arterial sistêmica, n (\%) & $16(34,8)$ & $13(38,2)$ & $6(24)$ & $16(41)$ & $51(35,4)$ & 0.555 \\
\hline Diabetes mellitus, $n(\%)$ & $6(13)$ & $9(26,5)$ & $2(8)$ & $11(28,2)$ & $28(19,4)$ & $0,085 \#$ \\
\hline Insuficiência coronariana, n (\%) & $1(2,2)$ & $2(5,9)$ & $0(0)$ & $1(2,6)$ & $4(2,8)$ & 0.492 \\
\hline Insuficiência cardíaca, n (\%) & $1(2,2)$ & $1(2,9)$ & $3(12)$ & $1(2,6)$ & $6(4,2)$ & $0,311 \#$ \\
\hline Tabagismo, n (\%) & $23(50)$ & $18(52,9)$ & $10(40)$ & $17(43,6)$ & $68(47,2)$ & 0.725 \\
\hline Noradrenalina, n (\%) & $25(54,3)$ & $21(61,8)$ & $20(80)$ & $29(74,4)$ & $95(66)$ & 0.092 \\
\hline Vasopressina, n (\%) & $0(0)$ & $4(11,8)$ & $3(12)$ & $8(20,5)$ & $15(10,4)$ & $0,003 \#$ \\
\hline Dobutamina, n (\%) & $5(10,9)$ & $5(14,7)$ & $5(20)$ & $5(12,8)$ & $20(13,9)$ & $0,769 \#$ \\
\hline Ventilação Mecânica, n (\%) & $3(6,5)$ & $10(29,4)$ & $5(20)$ & $16(42,1)$ & $34(23,8)$ & 0.002 \\
\hline Transfusão, n (\%) & $1(2,2)$ & $0(0)$ & $1(4)$ & $2(5,3)$ & $4(2,8)$ & $0,424 \#$ \\
\hline Tumor hematológico, n (\%) & $10(21,7)$ & $4(11,8)$ & $1(4)$ & $5(12,8)$ & $20(13,9)$ & $0,173 \#$ \\
\hline Metástase, n (\%) & $20(43,5)$ & $18(52,9)$ & $12(48)$ & $20(51,3)$ & $70(48,6)$ & 0.836 \\
\hline Cirurgia (últimos 3 meses), n (\%) & $6(13)$ & $0(0)$ & $2(8)$ & $2(5,1)$ & $10(6,9)$ & $0,063 \#$ \\
\hline Quimioterapia (últimos 3 meses), n (\%) & $27(58,7)$ & $20(58,8)$ & $17(68)$ & $19(48,7)$ & $83(57,6)$ & 0.492 \\
\hline Radioterapia, n (\%) & $10(21,7)$ & $9(26,5)$ & $8(32)$ & $10(25,6)$ & $37(25,7)$ & 0.823 \\
\hline Óbito, n (\%) & $19(41,3)$ & $26(76,5)$ & $21(84)$ & $32(82,1)$ & $98(68,1)$ & $<0,001$ \\
\hline
\end{tabular}

Os grupos foram homogêneos em relação às características demográficas e clínicas. Houve um predomínio de pacientes do sexo masculino nos grupos sem IRA, AKIN1, AKIN2 e AKIN3 (54,3\% vs. $58,8 \%$ vs. $60 \%$ vs. $56,4 \%$ respectivamente, $p=0,965)$. A média da idade foi semelhante entre os grupos (60 \pm 11 anos no grupo sem IRA, $62 \pm 13$ anos no grupo AKIN1, $56 \pm$ 15 anos no grupo AKIN2, $63 \pm 14$ anos no grupo AKIN3, $p=0,23)$. O índice de massa corporal (IMC) foi similar entre os grupos (24 \pm 5 vs. $23 \pm 4$ vs. $22 \pm 4$ vs. $23 \pm 6$, respectivamente sem IRA, AKIN1, AKIN2, AKIN3, p=0,54). Dentre as comorbidades estudadas, as mais frequentes foram hipertensão arterial (35\% no grupo sem IRA vs. $38 \%$ AKIN1 vs. $24 \%$ AKIN2 vs. $41 \%$ AKIN3, p= $0,555)$ e diabetes mellitus ( $13 \%$ no grupo sem IRA vs. $27 \%$ AKIN1 vs. $8 \%$ AKIN2 vs. $28 \%$ AKIN3, $p=0,085)$. A frequência de pacientes com insuficiência coronariana e insuficiência cardíaca congestiva foi baixa. A prevalência de 
tabagistas foi elevada em todos os grupos ( $50 \%$ no grupo sem IRA vs. $53 \%$ AKIN1 vs. $40 \%$ AKIN2 vs. $44 \%$ AKIN3, $p=0,725)$.

A causa de internação dos pacientes estudados na UTI foi sepse ou choque séptico. Entre os pacientes que necessitaram de drogas vasoativas, a noradrenalina foi a droga mais frequentemente utilizada, seguida de dobutamina e vasopressina. Pelo teste da razão de verossimilhança, verificouse que houve diferença estatística significativa na utilização da vasopressina entre os grupos (0\% no grupo sem IRA, 11,8\% AKIN1, 12\% AKIN2, $20,5 \%$ AKIN3, $p=0,003)$. Não houve diferença na frequência de utilização de noradrenalina $(54,3 \%$ no grupo sem IRA, 61,8\% AKIN1, 80\% AKIN2, 74,4\% AKIN3, $p=0,092)$ e dobutamina $(10,9 \%$ no grupo sem IRA, $14,7 \%$ AKIN1, $20 \%$ AKIN2, $12,8 \%$ AKIN3, $p=0,769$ ) entre os grupos. Não houve diferença no tempo de permanência na UTI entre os grupos (5,5 dias no grupo sem IRA vs. 8 dias AKIN1 vs. 6 dias AKIN2 vs. 8,5 dias AKIN3, $p=0,268)$.

O uso de ventilação mecânica ocorreu em $6,5 \%$ dos pacientes do grupo que não apresentou IRA, 29,4\% no grupo AKIN1, 20\% no grupo AKIN2 e $42,1 \%$ no grupo AKIN3 ( $p=0,002)$.

A transfusão de sangue e hemoderivados ocorreu em apenas 4 pacientes, de forma semelhante entre os grupos $(p=0,424)$.

Quanto ao diagnóstico oncológico, os tumores foram classificados em tumores sólidos ou hematológicos. Os tumores hematológicos corresponderam a $21,7 \%$ vs. $11,8 \%$ vs. $4 \%$ vs. $12,8 \%$ dos pacientes dos grupos sem IRA, AKIN1, AKIN2 e AKIN3, respectivamente $(p=0,173)$. 
Quanto ao estadiamento dos tumores, $43,5 \%$ vs. $52,9 \%$ vs. $48 \%$ vs. $51,3 \%$ dos pacientes dos grupos sem IRA, AKIN1, AKIN2, AKIN3, apresentavam metástases, respectivamente $(p=0,836)$.

Em relação ao tipo de tratamento oncológico recebido nos últimos 3 meses anteriores à inclusão no estudo, a quimioterapia foi a mais frequente (58,7\% no grupo sem IRA vs. $58,8 \%$ AKIN1 vs. $68 \%$ AKIN2 vs. $48,7 \%$ AKIN3, $p=0,492)$, seguida de radioterapia $(21,7 \%$ no grupo sem IRA vs. $26,5 \%$ AKIN1 vs. $32 \%$ AKIN2 vs. $25,6 \%$ AKIN3, $p=0,823)$ e cirurgia $(13 \%$ no grupo sem IRA vs. $0 \%$ AKIN1 vs. $8 \%$ AKIN2 vs. $5,1 \%$ AKIN3, $p=0,063)$.

A mortalidade foi menor no grupo de pacientes que não apresentou IRA (41,3\%), comparado com os grupos que apresentaram IRA $(76,5 \%$ para AKIN1 vs. $84 \%$ AKIN2 vs. $82,1 \%$ AKIN3, $p<0,001)$. Assim como observado na Tabela 1, o Gráfico 1 sugere que pacientes com qualquer grau de disfunção renal apresentaram maior mortalidade do que os pacientes sem IRA. 
Gráfico 1. Mortalidade segundo grau de IRA (AKIN)

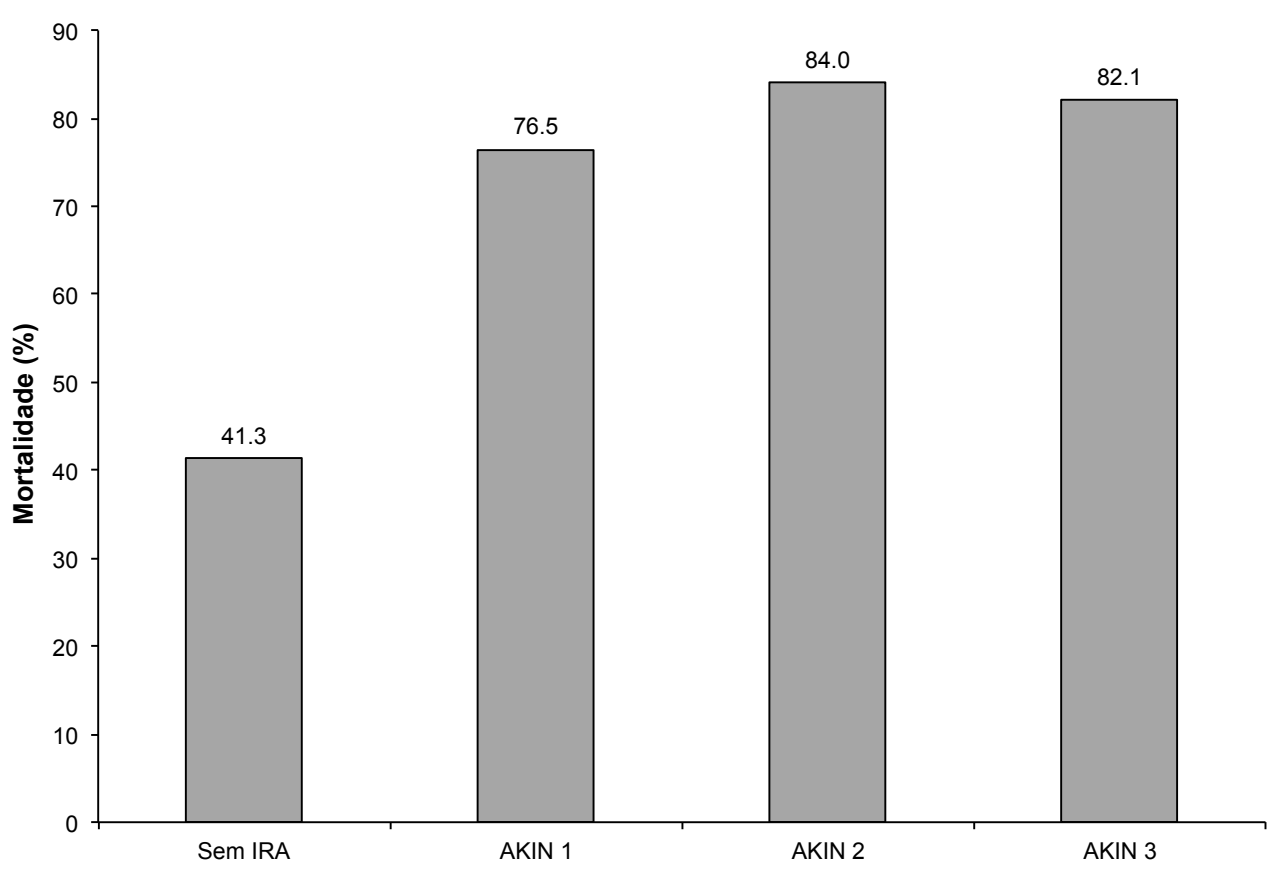

Os principais tipos de tumores na população estudada se encontram na Tabela 7.

TABELA 7. Tipos de tumores dos pacientes estudados

\begin{tabular}{lcc}
\hline Tipos de tumores agrupados & $\mathbf{n}$ & $\mathbf{\%}$ \\
\hline \hline colo retal & 23 & 16.0 \\
outros tumores TGI não colo-retal & 17 & 11.8 \\
hematológico & 20 & 13.9 \\
pulmão & 15 & 10.4 \\
vias biliares e pâncreas & 10 & 7.0 \\
mama & 12 & 8.3 \\
cabeça e pescoço & 13 & 9.0 \\
outros & 34 & 23.6 \\
\hline Total & $\mathbf{1 4 4}$ & $\mathbf{1 0 0}$ \\
\hline
\end{tabular}


O tipo de tumor mais frequente na casuística foi o câncer colo-retal (16\%), seguido de tumor hematológico $(13,9 \%)$, outros tumores do trato gastrointestinal não colo-retal $(11,8 \%)$, cabeça e pescoço $(9 \%)$, mama $(8,3 \%)$, vias biliares e pâncreas $(7,0 \%)$ e outros (sarcomas, próstata, sistema nervoso central, hepatocarcinoma, rim, ginecológico exceto mama).

Os principais resultados laboratoriais gerais entre os grupos estão apresentados na Tabela 8.

TABELA 8. Resultados laboratoriais gerais

\begin{tabular}{|c|c|c|c|c|c|}
\hline Variável & $\begin{array}{l}\text { Sem IRA } \\
(N=46)\end{array}$ & $\begin{array}{c}\text { AKIN 1 } \\
(\mathrm{N}=34)\end{array}$ & $\begin{array}{c}\text { AKIN 2 } \\
(\mathrm{N}=25)\end{array}$ & $\begin{array}{l}\text { AKIN 3 } \\
(\mathrm{N}=39)\end{array}$ & p \\
\hline Creatinina base $(\mathrm{mg} / \mathrm{dL})$ & $0,69(0,47 ; 0,75)$ & $1,01(0,96 ; 1,06)^{a}$ & $0,48(0,39 ; 0,89)^{D}$ & $0,91(0,64 ; 1,19)$ & 0.047 \\
\hline Creatinina máxima $(\mathrm{mg} / \mathrm{dL})$ & $0,85(0,48 ; 0,9)$ & $1,88(1,55 ; 1,91)^{a}$ & $1,07(0,89 ; 1,92)^{a}$ & $3,02(2,2 ; 6,17)^{\mathrm{abc}}$ & $<0,001$ \\
\hline Uréia $(\mathrm{mg} / \mathrm{dL})$ & $52(41 ; 56)$ & $89(80,5 ; 106)^{a}$ & $73,5(51 ; 91)^{a}$ & $134(99 ; 196)^{a b c}$ & $<0,001$ \\
\hline $\mathrm{Na}(\mathrm{mEq} / \mathrm{L})$ & $140,5(138 ; 145)$ & $140(137,5 ; 140,5)$ & $139,5(138 ; 142)$ & $144(140 ; 149)^{a}$ & 0.026 \\
\hline $\mathrm{K}(\mathrm{mEq} / \mathrm{L})$ & $3,25(3,1 ; 3,8)$ & $3,4(3,25 ; 3,75)$ & $3,25(3 ; 3,8)$ & $4,4(3,2 ; 5,8)^{a b c}$ & 0.012 \\
\hline Cai $(\mathrm{mg} / \mathrm{dL})$ & $4,65(4,6 ; 4,8)$ & $4,5(4,5 ; 4,6)$ & $4,95(4,3 ; 5)$ & $4,45(4,3 ; 4,7)$ & 0.365 \\
\hline $\mathrm{P}(\mathrm{mg} / \mathrm{dL})$ & $3,05(2,1 ; 3,8)$ & $3,7(3,1 ; 4,7)^{a}$ & $4,35(3,8 ; 4,9)^{a}$ & $5,1(4,4 ; 6,1)^{a b}$ & $<0,001$ \\
\hline $\mathrm{Mg}(\mathrm{mg} / \mathrm{dL})$ & $1,84(1,71 ; 2,08)$ & $2,15(1,94 ; 2,24)$ & $1,91(1,74 ; 1,95)^{a}$ & $2,16(1,89 ; 2,24)^{a b}$ & $<0,001$ \\
\hline Albumina $(\mathrm{g} / \mathrm{dL})$ & $3,4(2,8 ; 3,6)$ & $2,5(2,35 ; 2,55)^{a}$ & $3,05(2,7 ; 3,3)$ & $2,4(2,3 ; 2,5)^{a}$ & 0.022 \\
\hline $\operatorname{ALT}(U / L)$ & $23,5(16 ; 85)$ & $24(16,5 ; 26,5)$ & $34(26 ; 219)$ & $30(21 ; 572)$ & 0.141 \\
\hline AST (U/L) & $29,5(17 ; 65)$ & $20,9(17,45 ; 23,45)$ & $84(30 ; 708)$ & $49(17 ; 976)$ & 0.173 \\
\hline $\mathrm{PCR}(\mathrm{mg} / \mathrm{L})$ & $56,15(38 ; 132,5)$ & $221(163,75 ; 223,85)$ & $72,65(51,4 ; 258)$ & $116,35(71,7 ; 187)$ & 0.661 \\
\hline $\mathrm{pH}$ & $7,41(7,39 ; 7,44)$ & $7,36(7,32 ; 7,4)$ & $7,38(7,34 ; 7,42)$ & $7,27(7,18 ; 7,32)^{a b}$ & 0.001 \\
\hline Bicarbonato $(\mathrm{mmol} / \mathrm{L})$ & $28,3(26 ; 29,5)$ & $19,2(18,65 ; 22,8)^{a}$ & $20,7(19,8 ; 29,8)^{\mathrm{a}}$ & $20,3(17,8 ; 21,8)^{a}$ & $<0,001$ \\
\hline Lactato (mg/dL) & $16(12 ; 23)$ & $15(13 ; 17,5)$ & $14,5(12 ; 17)^{a}$ & $25,5(21 ; 45)^{a b}$ & $<0,001$ \\
\hline Glicose (mg/dL) & $125,5(108 ; 167)$ & $127(103 ; 148,5)^{a}$ & $121(88 ; 179)$ & $107,5(104 ; 216)^{a c}$ & 0.003 \\
\hline
\end{tabular}

Dados expressos em mediana (Q1; Q3); Teste Kruskal-Wallis

(a) vs. grupo sem IRA, p<0,05; (b) vs. AKIN1, p <0,05; (c) vs. AKIN2, p<0,05

Houve diferença estatisticamente significativa nos resultados entre os grupos nos seguintes parâmetros laboratoriais: creatinina de base, creatinina máxima, uréia, sódio, potássio, fósforo, magnésio, albumina, $\mathrm{pH}$, bicarbonato, lactato e glicose. As diferenças entre os grupos estão indicadas em sobrescrito na Tabela 8. Não houve diferença estatisticamente significativa entre os grupos 
para os seguintes parâmetros: cálcio iônico, alanina-aminotransferase (ALT), aspartato-aminotransferase (AST) e proteína $\mathrm{C}$ reativa ( $\mathrm{PCR}$ ).

Os resultados laboratoriais relacionados ao perfil da hemostasia estão demonstrados na Tabela 9.

TABELA 9. Resultados laboratoriais hematológicos

\begin{tabular}{|c|c|c|c|c|c|}
\hline Variável & $\begin{array}{c}\text { Sem IRA } \\
(N=46)\end{array}$ & $\begin{array}{c}\text { AKIN } 1 \\
(N=34)\end{array}$ & $\begin{array}{l}\text { AKIN 2 } \\
(N=25)\end{array}$ & $\begin{array}{r}\text { AKIN } 3 \\
(\mathrm{~N}=39)\end{array}$ & p \\
\hline Hemoglobina (g/dL) & $8,45(8,1 ; 11,5)$ & "10,3(10,2; 11,55) & $9(8 ; 9,4)$ & $10,2(8,8 ; 11,2)$ & 0.094 \\
\hline Hematócrito (\%) & $26,2(25,4 ; 32,8)$ & $31,6(30,65 ; 34,95)$ & $27,75(24 ; 28,9)$ & $32,8(27,1 ; 33,4)$ & 0.094 \\
\hline Plaquetas (mil/mm3) & $119,5(44 ; 180)$ & $90(61,5 ; 134)$ & $214(89 ; 258)$ & $211,5(59 ; 303)$ & 0.392 \\
\hline TP - INR & $1,1(1,08 ; 1,29)$ & $1,34(1,25 ; 1,68)^{a}$ & $1,4(1,11 ; 1,97)^{a}$ & $1,98(1,39 ; 2,81)^{a b}$ & $<0,001$ \\
\hline TT relacao & $1,08(1,01 ; 1,16)$ & $1,13(1,08 ; 1,16)$ & $1,1(1,04 ; 1,46)^{a}$ & $1,19(1,14 ; 1,31)^{a b}$ & $<0,001$ \\
\hline TTPA-R & $1,01(0,87 ; 1,09)$ & $1,31(1,11 ; 1,38)^{a}$ & $1,21(1,02 ; 1,34)^{a}$ & $1,1(1 ; 1,32)^{a}$ & 0.005 \\
\hline Fibrinogênio (mg/dl) & $484(369 ; 548)$ & $413(412,5 ; 524)$ & $418(290 ; 488)$ & $315,5(264 ; 600)$ & 0.204 \\
\hline D-dímero (ng/ml) & $1077,5(807 ; 2328)$ & $837(830,5 ; 3267)^{\text {a }}$ & $902(736 ; 2320)^{a}$ & $1717(1133 ; 3180)^{a}$ & 0.001 \\
\hline Fator VIII (\%) & $235(182 ; 316)$ & $208(196 ; 240)$ & $301(187 ; 366)^{\mathrm{b}}$ & $247(160 ; 330)^{b}$ & 0.007 \\
\hline
\end{tabular}

Dados expressos em mediana (Q1; Q3); Teste Kruskal-Wallis

Valores de referência: fibrinogênio $=220-496 \mathrm{mg} / \mathrm{dL} ;$ D-dímero $=232 \mathrm{ng} / \mathrm{mL}$ (limite superior da normalidade); fator VIII $=50-150 \%$

(a) vs. grupo sem IRA, p<0,05; (b) vs. AKIN1, p<0,05; (c) vs. AKIN2, $p<0,05$

Os valores da hemoglobina, hematócrito, plaquetas e fibrinogênio não tiveram diferenças significativas entre os grupos. Em relação aos parâmetros laboratoriais de coagulação, houve diferença estatisticamente significativa entre os grupos quanto ao tempo de protrombina (TP), tempo de trombina (TT) e tempo de tromboplastina parcial ativada (TTPa). Observou-se que o TP, TT e TTPa apresentaram resultado maior no grupo de pacientes que tiveram IRA, mostrando piora dos parâmetros de coagulação do grupo com IRA comparado com o grupo que não apresentou IRA. Também houve diferença significativa entre os grupos quanto aos resultados de D-dímero e fator VIII. 
A avaliação da função plaquetária pelo Impact- $^{\circledR}$, apresentada na Tabela 10, não mostrou diferença entre os grupos na variável AS (average size), ou seja, os grupos foram semelhantes quanto à agregação plaquetária. Entretanto, os resultados estavam acima ou no limite superior da faixa de referência. A adesão plaquetária, indicada pela variável SC (surface covered), foi maior no grupo AKIN 3 e houve diferença estatisticamente significativa entre o grupo AKIN 3 e o grupo sem IRA $(p=0,026)$.

TABELA 10. Avaliação da adesão e agregação plaquetária pelo Impact- $R^{\circledR}$

\begin{tabular}{|c|c|c|c|c|c|}
\hline Variável & $\begin{array}{l}\text { Sem IRA } \\
(\mathrm{N}=46)\end{array}$ & $\begin{array}{c}\text { AKIN } 1 \\
(\mathrm{~N}=34)\end{array}$ & $\begin{array}{c}\text { AKIN 2 } \\
(\mathrm{N}=25) \\
\end{array}$ & $\begin{array}{r}\text { AKIN 3 } \\
(\mathrm{N}=39) \\
\end{array}$ & p \\
\hline SC (\%) & $10(8 ; 11)$ & $15(12,5 ; 16)$ & $11(10 ; 18)$ & $16,5(13 ; 18)^{a}$ & 0.026 \\
\hline AS (mm2) & $52,5(34 ; 65)$ & $66(60,5 ; 69)$ & $50(44 ; 58)$ & $54(51 ; 60)$ & 0.139 \\
\hline
\end{tabular}

Dados expressos em mediana (Q1; Q3); Teste Kruskal-Wallis

Valores de referência: SC $11,6 \% \pm 5$; AS $39,8 \mathrm{~mm}^{2} \pm 11,9$

(a) vs. grupo sem IRA, $p<0,05$

O resultado da tromboelastografia, que fornece o perfil global da coagulação continuamente, desde o início da formação de coágulo até a fibrinólise, se encontra na Tabela 11.

TABELA 11. Resultados da tromboelastografia

\begin{tabular}{lccccc}
\hline Variável & $\begin{array}{c}\text { Sem IRA } \\
(\mathbf{N}=\mathbf{4 6})\end{array}$ & $\begin{array}{c}\text { AKIN } \\
(\mathbf{N}=\mathbf{3 4})\end{array}$ & $\begin{array}{c}\text { AKIN 2 } \\
(\mathbf{N}=\mathbf{2 5})\end{array}$ & $\begin{array}{c}\text { AKIN 3 } \\
(\mathbf{N}=39)\end{array}$ & $\mathbf{p}$ \\
\hline \hline $\mathrm{R}(\min )$ & $8,3(6,6 ; 9,8)$ & $9,2(7,65 ; 10,35)$ & $7,95(7,1 ; 10,8)$ & $10,1(8,2 ; 10,6)^{\mathrm{a}}$ & $\mathbf{0 . 0 1 7}$ \\
$\mathrm{K}(\min )$ & $2,35(1,7 ; 3,2)$ & $2,7(2,2 ; 3,25)$ & $2,75(2,3 ; 3,5)$ & $2,8(2,2 ; 3,6)^{\mathrm{a}}$ & $\mathbf{0 . 0 0 5}$ \\
Angulo (grau) & $57,5(51,4 ; 65,2)$ & $56,8(51,2 ; 61,25)$ & $56,9(46,6 ; 58,9)$ & $56,25(46,6 ; 58,4)^{a}$ & $\mathbf{0 . 0 0 4}$ \\
MA (mm) & $60,65(51 ; 61,8)$ & $63(61,95 ; 64,65)$ & $62,7(60,6 ; 69,3)$ & $60,85(50,1 ; 70,9)$ & 0.541 \\
Cl & $1,65(-0,1 ; 2,2)$ & $1,8(1,5 ; 2,35)$ & $1,75(0,6 ; 1,9)$ & $1,7(-0,3 ; 3)$ & 0.557 \\
\hline
\end{tabular}

Dados expressos em mediana (Q1; Q3); Teste Kruskal-Wallis

Valores de referência: $\mathrm{R}=5-10 ; \mathrm{K}=1-3$; ângulo = 45-74; $\mathrm{MA}=54-62 ; \mathrm{Cl}=-3-3$

(a) vs. grupo sem IRA, $p<0,05$ 
O tempo de reação $(R)$, que representa o tempo entre a colocação da amostra de sangue no analisador até a formação inicial de fibrina, foi maior no grupo AKIN 3 (vs. grupo sem IRA, $p=0,017$ ).

O tempo $\mathrm{K}(\mathrm{K})$, que representa o tempo entre o início da formação da fibrina até o nível de firmeza padrão, foi maior no grupo AKIN 3 (vs. grupo sem IRA, $p=0,005)$.

O ângulo, que mede a rapidez da formação de fibrina e firmeza do coágulo, foi menor no grupo AKIN3 (vs. grupo sem IRA, $p=0,004$ ).

A amplitude máxima (MA), que representa a força do coágulo de fibrina, não apresentou diferença estatisticamente significativa entre os grupos ( $p=$ $0,541)$.

Apesar dos parâmetros $\mathrm{R}, \mathrm{K}$ e ângulo terem apresentado diferenças entre os grupos, o índice de coagulação $(\mathrm{Cl})$, que representa a coagulação global do paciente utilizando os parâmetros $R, K$, ângulo e MA, não mostrou diferença entre os grupos $(p=0,557)$.

A mensuração da atividade de trombina foi realizada pelo Thrombinoscope ${ }^{\circledR}$ e os resultados organizados na Tabela 12.

TABELA 12. Teste da geração de trombina

\begin{tabular}{|c|c|c|c|c|c|}
\hline Variável & $\begin{array}{c}\text { Sem IRA } \\
(\mathrm{N}=46)\end{array}$ & $\begin{array}{l}\text { AKIN } 1 \\
(\mathrm{~N}=34) \\
\end{array}$ & $\begin{array}{c}\text { AKIN 2 } \\
(\mathrm{N}=25) \\
\end{array}$ & $\begin{array}{l}\text { AKIN 3 } \\
(\mathrm{N}=39) \\
\end{array}$ & p \\
\hline ETP-5pM (nmol/L x min) & $1410,15(1083 ; 1663,7)$ & $855,3(849 ; 1082)$ & $1053,85(422,7 ; 1293)^{a}$ & $912,65(627,3 ; 2060,7)^{a}$ & 0.021 \\
\hline ETP-High (nmol/L x min) & $1568,15(1407,3 ; 1845)$ & $1389,3(1184,65 ; 1398,65)$ & $1368,65(1214,3 ; 1589)$ & $1071,5(978,7 ; 2248,7)$ & 0.090 \\
\hline
\end{tabular}


A área sob a curva, parâmetro analisado no teste da geração de trombina, também conhecido como potencial endógeno de trombina (ETP), não apresentou diferença entre os grupos utilizando-se PPP-reagent High ( $p=$ 0,09). Utilizando-se o PPP-reagent 5pM, observou-se diferença entre os grupos $(p=0,021)$. Houve menor geração de trombina no grupo AKIN2 e AKIN3, comparado com o grupo sem IRA $(p<0,05)$.

A Tabela 13 mostra que pacientes com maior tempo na UTI apresentaram estatisticamente maior chance de óbito $(p<0,001)$, assim como aqueles que fizeram uso de vasopressina ou ventilação mecânica ( $p=0,037$ e $p=0,004$, respectivamente).

Tabela 13. Descrição dos dados demográficos e clínicos segundo mortalidade

\begin{tabular}{|c|c|c|c|c|c|c|c|}
\hline \multirow{2}{*}{ Variável } & \multirow{2}{*}{$\begin{array}{c}\text { Vivo } \\
(\mathrm{N}=46)\end{array}$} & \multirow{2}{*}{$\begin{array}{c}\text { Óbito } \\
(\mathrm{N}=98)\end{array}$} & \multirow{2}{*}{ OR } & \multicolumn{2}{|c|}{ IC (95\%) } & \multirow{2}{*}{$\begin{array}{c}\text { Total } \\
(\mathrm{N}=144)\end{array}$} & \multirow{2}{*}{$\mathbf{p}$} \\
\hline & & & & Inferior & Superior & & \\
\hline Sexo (masculino), n (\%) & $23(50)$ & $59(60,2)$ & 1.51 & 0.75 & 3.06 & $82(56,9)$ & 0.249 \\
\hline Idade (anos), média (DP) & $60,48(13,69)$ & $61,04(13,38)$ & 1.00 & 0.98 & 1.03 & $60,86(13,43)$ & $0,816^{* *}$ \\
\hline IMC, média (DP)\& & $23,97(6,72)$ & $22,89(4,18)$ & 0.96 & 0.89 & 1.03 & $23,24(5,15)$ & $0,357^{* *}$ \\
\hline Tempo na UTI (dias) & $3(2 ; 5)$ & $7,5(6 ; 10)$ & 1.15 & 1.06 & 1.24 & $7(3 ; 10)$ & $<0,001 £$ \\
\hline Hipertensão arterial sistêmica, n (\%) & $15(32,6)$ & $36(36,7)$ & 1.20 & 0.57 & 2.52 & $51(35,4)$ & 0.629 \\
\hline Diabetes mellitus, $\mathrm{n}(\%)$ & $5(10,9)$ & $23(23,5)$ & 2.52 & 0.89 & 7.11 & $28(19,4)$ & 0.075 \\
\hline Insuficiência coronariana, n (\%) & $1(2,2)$ & $3(3,1)$ & 1.42 & 0.14 & 14.04 & $4(2,8)$ & $>0,999^{*}$ \\
\hline Insuficiência cardíaca, n (\%) & $2(4,3)$ & $4(4,1)$ & 0.94 & 0.17 & 5.31 & $6(4,2)$ & $>0,999^{*}$ \\
\hline Tabagismo, n (\%) & $21(45,7)$ & $47(48)$ & 1.10 & 0.54 & 2.22 & $68(47,2)$ & 0.796 \\
\hline Noradrenalina, $\mathrm{n}(\%)$ & $28(60,9)$ & $67(68,4)$ & 1.39 & 0.67 & 2.88 & $95(66)$ & 0.376 \\
\hline Vasopressina, $\mathrm{n}(\%)$ & $1(2,2)$ & $14(14,3)$ & 7.50 & 0.96 & 58.89 & $15(10,4)$ & $0,037^{*}$ \\
\hline Dobutamina, n (\%) & $7(15,2)$ & $13(13,3)$ & 0.85 & 0.32 & 2.30 & $20(13,9)$ & 0.752 \\
\hline Ventilação Mecânica, n (\%) & $4(8,7)$ & $30(30,9)$ & 4.70 & 1.55 & 14.30 & $34(23,8)$ & 0.004 \\
\hline Transfusão, n (\%) & $0(0)$ & $4(4,1)$ & \# & & & $4(2,8)$ & $0,305^{*}$ \\
\hline Tumor hematológico, n (\%) & $7(15,2)$ & $13(13,3)$ & 0.85 & 0.32 & 2.30 & $20(13,9)$ & 0.752 \\
\hline Metástase, n (\%) & $18(39,1)$ & $52(53,1)$ & 1.76 & 0.86 & 3.59 & $70(48,6)$ & 0.119 \\
\hline Cirurgia (últimos 3 meses), n (\%) & $5(10,9)$ & $5(5,1)$ & 0.44 & 0.12 & 1.61 & $10(6,9)$ & $0,290^{*}$ \\
\hline Quimioterapia (últimos 3 meses), n (\%) & $31(67,4)$ & $52(53,1)$ & 0.55 & 0.26 & 1.14 & $83(57,6)$ & 0.105 \\
\hline Radioterapia, n (\%) & $14(30,4)$ & $23(23,5)$ & 0.70 & 0.32 & 1.53 & $37(25,7)$ & 0.372 \\
\hline
\end{tabular}

A Tabela 14 mostra que aqueles pacientes que apresentavam maiores valores para creatinina máxima, tinham maior probabilidade de óbito $(p=$ $0,001)$, assim como maiores valores de uréia $(p<0,001)$, sódio $(p<0,001)$, fósforo $(p=0,001)$, magnésio $(p<0,001)$, PCR $(P=0,001)$ e lactato $(p<0,001)$. 
Além disso, aqueles com valores menores de albumina também apresentavam maior probabilidade de óbito.

Tabela 14. Resultados laboratoriais gerais e mortalidade

\begin{tabular}{|c|c|c|c|c|c|c|c|}
\hline \multirow{2}{*}{ Variável } & \multirow{2}{*}{$\begin{array}{c}\text { Vivo } \\
(N=46)\end{array}$} & \multirow{2}{*}{$\begin{array}{c}\text { Óbito } \\
(N=98)\end{array}$} & \multirow{2}{*}{ OR } & \multicolumn{2}{|c|}{ IC (95\%) } & \multirow{2}{*}{$\begin{array}{c}\text { Total } \\
(\mathrm{N}=144)\end{array}$} & \multirow{2}{*}{$\mathbf{p}$} \\
\hline & & & & Inferior & Superior & & \\
\hline Creatinina base $(\mathrm{mg} / \mathrm{dL})$ & $\overline{0,68(0,52 ; 0,72)}$ & $\overline{0.88(0,55 ; 1,01)}$ & 1.18 & 0.46 & 2.98 & $\overline{0,74(0,55 ; 0,95)}$ & 0.546 \\
\hline Creatinina máxima (mg/dL) & $0,89(0,72 ; 0,95)$ & $1,53(0,89 ; 2,35)$ & 1.40 & 1.02 & 1.92 & $1,2(0,86 ; 1,93)$ & 0.001 \\
\hline Uréia (mg/dL) & $44(30 ; 61)$ & $84(55 ; 123)$ & 1.02 & 1.01 & 1.02 & $66(49 ; 99)$ & $<0,001$ \\
\hline $\mathrm{Na}(\mathrm{mEq} / \mathrm{L})$ & $138(137,5 ; 140)$ & $141(140 ; 147)$ & 1.11 & 1.04 & 1.18 & $140(138 ; 143)$ & $<0,001$ \\
\hline $\mathrm{K}(\mathrm{mEq} / \mathrm{L})$ & $3,4(3,2 ; 3,65)$ & $3,25(3,1 ; 3,8)$ & 1.26 & 0.75 & 2.10 & $3,3(3,1 ; 3,8)$ & 0.828 \\
\hline Cai $(\mathrm{mg} / \mathrm{dL})$ & $4,5(4,49 ; 4,6)$ & $4,7(4,5 ; 4,8)$ & 1.35 & 0.61 & 2.97 & $4,6(4,5 ; 4,8)$ & 0.584 \\
\hline $\mathrm{P}(\mathrm{mg} / \mathrm{dL})$ & $3,4(1,9 ; 3,9)$ & $4,25(3,7 ; 5,6)$ & 1.45 & 1.12 & 1.87 & $3,9(2,7 ; 4,6)$ & 0.001 \\
\hline $\mathrm{Mg}(\mathrm{mg} / \mathrm{dL})$ & $1,73(1,66 ; 1,88)$ & $1,96(1,79 ; 2,15)$ & 5.51 & 1.79 & 16.91 & $1,91(1,74 ; 2,12)$ & $<0,001$ \\
\hline Albumina $(\mathrm{g} / \mathrm{dL})$ & $3,3(3,05 ; 3,5)$ & $2,6(2,5 ; 3,2)$ & 0.25 & 0.07 & 0.96 & $2,8(2,5 ; 3,4)$ & 0.050 \\
\hline $\operatorname{ALT}(U / L)$ & $22(17 ; 32,5)$ & $29(21 ; 109)$ & 1.000 & 0.997 & 1.002 & $28(18 ; 85)$ & 0.388 \\
\hline AST (U/L) & $30(17 ; 36,5)$ & $38(19 ; 128)$ & 1.001 & 0.999 & 1.002 & $30(17 ; 73)$ & 0.143 \\
\hline $\mathrm{PCR}(\mathrm{mg} / \mathrm{L})$ & $52(34,9 ; 123,4)$ & $112,55(59 ; 226,7)$ & 1.005 & 1.001 & 1.009 & $93,3(51,4 ; 187)$ & 0.001 \\
\hline $\mathrm{pH}$ & $7,39(7,38 ; 7,43)$ & $7,38(7,3 ; 7,41)$ & 0.02 & 0.00 & 2.33 & $7,39(7,32 ; 7,42)$ & 0.123 \\
\hline Bicarbonato (mmol/L) & $23,5(21,4 ; 27,75)$ & $23,5(19,2 ; 28,6)$ & 0.95 & 0.89 & 1.01 & $23,5(19,8 ; 28,6)$ & 0.089 \\
\hline Lactato $(\mathrm{mg} / \mathrm{dL})$ & $13(11,5 ; 18,5)$ & $18,5(15 ; 24)$ & 1.08 & 1.03 & 1.14 & $17(13 ; 23)$ & $<0,001$ \\
\hline Glicose (mg/dL) & $108(101,5 ; 152,5)$ & $125,5(107 ; 170)$ & 1.01 & 1.00 & 1.01 & $124(106 ; 170)$ & 0.054 \\
\hline
\end{tabular}

Teste Mann-Whitney; Estimativas de OR com uso de regressão logística bivariada

Na Tabela 15, observa-se que o número de plaquetas, TP, TT, TTPa e D-dímero foram estatisticamente diferentes entre pacientes que morreram e os que sobreviveram $(p<0,05)$.

Tabela 15. Descrição dos exames laboratoriais segundo mortalidade e resultado dos testes estatísticos

\begin{tabular}{|c|c|c|c|c|c|c|c|}
\hline \multirow{2}{*}{ Variável } & \multirow{2}{*}{$\begin{array}{c}\text { Vivo } \\
(\mathrm{N}=46) \\
\end{array}$} & \multirow{2}{*}{$\begin{array}{c}\text { Obito } \\
(\mathrm{N}=98)\end{array}$} & \multirow{2}{*}{ OR } & \multicolumn{2}{|c|}{ IC $(95 \%)$} & \multirow{2}{*}{$\begin{array}{c}\text { Total } \\
(\mathrm{N}=144)\end{array}$} & \multirow{2}{*}{$\mathrm{p}$} \\
\hline & & & & Inferior & Superior & & \\
\hline Hemoglobina (g/dL) & $9,1(8,55 ; 10,45)$ & $9,75(8,2 ; 10,3)$ & 0.95 & 0.79 & 1.15 & $9,4(8,3 ; 10,3)$ & 0.530 \\
\hline Hematócrito (\%) & $27,6(25,9 ; 29,9)$ & $30,35(25,7 ; 33,3)$ & 0.99 & 0.93 & 1.05 & $28,9(25,8 ; 32,8)$ & 0.600 \\
\hline Plaquetas (mil/mm3) & $132(98 ; 223)$ & $167,5(57 ; 222)$ & 0.998 & 0.995 & 1.000 & $160(59 ; 222)$ & 0.010 \\
\hline TP - INR & $1,14(1,1 ; 1,34)$ & $1,37(1,1 ; 2,01)$ & 6.40 & 1.95 & 21.00 & $1,29(1,1 ; 1,89)$ & $<0,001$ \\
\hline TT relacao & $1,21(1,03 ; 1,23)$ & $1,12(1,06 ; 1,16)$ & 11.84 & 1.74 & 80.48 & $1,13(1,04 ; 1,21)$ & 0.008 \\
\hline TTPA-R & $1,02(1 ; 1,09)$ & $1,1(0,91 ; 1,31)$ & 12.94 & 2.26 & 74.29 & $1,09(0,98 ; 1,23)$ & 0.004 \\
\hline Fibrinogênio (mg/dl) & $480(353,5 ; 544)$ & $435,5(343 ; 521)$ & 0.999 & 0.996 & 1.001 & $458(351 ; 521)$ & 0.371 \\
\hline D-dímero (ng/ml) & $736(533 ; 1360)$ & $1224(858 ; 2339)$ & 1.001 & 1.000 & 1.001 & $1133(824 ; 2328)$ & $<0,001$ \\
\hline Fator VIII (\%) & $291(246 ; 324)$ & $205(182 ; 326)$ & 1.001 & 0.998 & 1.004 & $268(184 ; 326)$ & 0.841 \\
\hline
\end{tabular}

A Tabela 16 demonstra que o ETP-5pM e ETP-High foram estatisticamente menores nos pacientes que morreram ( $p=0,003$ e $p=0,004$ 
respectivamente), o parâmetro $R$ e o ângulo na tromboelastografia foram estatisticamente maiores em pacientes que evoluíram para óbito $(p=0,004$ e $p=$ 0,008, respectivamente).

Tabela 16. Descrição das variáveis de adesão e agregação plaquetária, geração de trombina e tromboelastografia segundo mortalidade

\begin{tabular}{|c|c|c|c|c|c|c|c|}
\hline \multirow{2}{*}{ Variável } & \multirow{2}{*}{$\begin{array}{c}\text { Vivo } \\
(\mathrm{N}=46)\end{array}$} & \multirow{2}{*}{$\begin{array}{c}\text { Obito } \\
(\mathrm{N}=98)\end{array}$} & \multirow{2}{*}{ OR } & \multicolumn{2}{|c|}{ IC (95\%) } & \multirow{2}{*}{$\begin{array}{c}\text { Total } \\
(\mathrm{N}=144)\end{array}$} & \multirow{2}{*}{ p } \\
\hline & & & & Inferior & Superior & & \\
\hline SC (\%) & 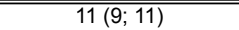 & "13,5(9;17) & 1.04 & 0.97 & $\begin{array}{ll}1.12 \\
\end{array}$ & $11(9 ; 15)$ & 0.141 \\
\hline AS (mm2) & $49(46 ; 59)$ & $56,5(47 ; 65)$ & 1.02 & 1.00 & 1.05 & $55(47 ; 65)$ & 0.080 \\
\hline ETP-5pM (nmol/L x min) & $1403(1038 ; 1571,7)$ & $1060,15(855,3 ; 1417,3)$ & 0.999 & 0.998 & 1.000 & $1148(901,3 ; 1459,7)$ & 0.003 \\
\hline ETP-High (nmol/L x min) & $1573,3(1431,35 ; 1717)$ & $1398,3(1029,7 ; 1796,7)$ & 0.999 & 0.998 & 1.000 & $1408(1214,3 ; 1796,7)$ & 0.004 \\
\hline $\mathrm{R}(\mathrm{min})$ & $8,2(7,35 ; 11,65)$ & $9,35(7,1 ; 10,6)$ & 1.15 & 1.02 & 1.29 & $8,8(7,1 ; 10,6)$ & 0.004 \\
\hline $\mathrm{K}(\min )$ & $2,8(2,3 ; 3,9)$ & $2,5(2,2 ; 3,5)$ & 1.06 & 0.91 & 1.23 & $2,7(2,2 ; 3,5)$ & 0.481 \\
\hline Angulo (grau) & $56,2(48,65 ; 58,65)$ & $57,15(46,6 ; 60,7)$ & 0.966 & 0.938 & 0.995 & $56,8(46,6 ; 59,8)$ & 0.008 \\
\hline $\mathrm{MA}(\mathrm{mm})$ & $61,8(61 ; 66,5)$ & $61,05(52,5 ; 66,3)$ & 0.99 & 0.96 & 1.02 & $61,4(52,6 ; 66,3)$ & 0.349 \\
\hline $\mathrm{Cl}$ & $1,7(0,5 ; 2,4)$ & $1,7(0,6 ; 2,3)$ & 0.88 & 0.73 & 1.07 & $1,7(0,6 ; 2,3)$ & 0.128 \\
\hline
\end{tabular}

Foi estimado pelo modelo de regressão logística múltipla para verificar conjuntamente as variáveis que influenciaram na mortalidade, selecionando-se as variáveis que nos testes bivariados apresentaram significância estatística $(p<0,05)$ e as variáveis que clinicamente podem influenciar na mortalidade. Os resultados se encontram na Tabela 17.

Tabela 17. Variáveis que influenciaram na mortalidade, após regressão logística

\begin{tabular}{lcccc}
\hline \multirow{2}{*}{ Variável } & \multirow{2}{*}{ OR } & IC (95\%) & \multirow{2}{*}{$\mathbf{p}$} \\
\cline { 3 - 4 } & & Inferior & Superior & \\
\hline \hline Ventilação Mecânica & 12.50 & 2.16 & 72.37 & 0.005 \\
PCR & 1.01 & 1.01 & 1.02 & 0.001 \\
ETP-5pM (100nmol) & 0.819 & 0.673 & 0.996 & 0.002 \\
IRA (AKIN 1 a 3) & 3.11 & 1.23 & 7.88 & 0.017 \\
\hline
\end{tabular}


A Tabela 17 demonstra que pacientes que fizeram uso de ventilação mecânica apresentaram chance de óbito 12,5 vezes em comparação com pacientes que não usaram ventilação mecânica.

O aumento de $1 \mathrm{mg} / \mathrm{dL}$ no PCR acarreta aumento de $1 \%$ na chance de óbito, enquanto que o aumento de 100 nM no ETP-5pM acarreta redução de $18,1 \%$ na chance de óbito.

Pacientes com qualquer grau de disfunção renal (AKIN 1 a 3 ) apresentam chance de óbito 3,11 vezes em comparação com pacientes sem IRA, independente das demais características dos pacientes. 


\section{DISCUSSÃO}

O objetivo do estudo consistiu em analisar as características clínicas e laboratoriais entre os diferentes graus de IRA e avaliar a influência da disfunção renal no perfil da hemostasia.

A anemia é comumente encontrada nos pacientes em UTI. Entre suas principais causas estão as múltiplas punções venosas a que os pacientes são submetidos, depleção nutricional e de fatores hematopoéticos (redução da produção de eritropoetina), diminuição da vida útil das hemácias, perdas pelo trato gastrointestinal e circuitos extra-corpóreos (50). A diminuição do número de hemácias circulantes faz com que as plaquetas percorram mais pela região central dos vasos sanguíneos, reduzindo a interação com o endotélio. As hemácias também liberam ADP e tromboxane $A_{2}$, portanto, diminuição da quantidade de hemácias resulta na diminuição da agregação plaquetária (47). Na nossa casuística, a anemia estava presente no grupo de pacientes sem IRA e com diversos graus de IRA, sendo que não houve diferença estatística significativa nos níveis de hemoglobina e hematócrito $(p=0,094)$. Desta forma, em princípio, nos pacientes estudados haveria uma menor interação entre as plaquetas e o endotélio.

Como se sabe, é descrito na literatura que o acúmulo de toxinas urêmicas secundário à disfunção renal pode predispor os pacientes ao sangramento (47). O primeiro e importante fator que contribui para $\mathrm{O}$ sangramento na uremia é a disfunção do fator de vonWillebrand (FvW). Essa molécula de adesão é reconhecida pelos receptores GPIb/IX. A ligação FvW a 
esses receptores inicia uma série de reações bioquímicas intracelulares, resultando na produção de tromboxane $A_{2}$. A interação entre FvW e GPIb/IX facilita a ativação do receptor GPIv/IIla, que permite a agregação plaquetária. Nos pacientes urêmicos com disfunção plaquetária, há defeito funcional no FvW devido à redução da afinidade de ligação com o receptor GPIb/IX ou da expressão reduzida dos receptores de GPIb/IX plaquetários. A fraca interação entre FvW e receptor GPIb/IX resulta na redução da produção de tromboxane $A_{2}$ e ADP. Há também redução da função do fator VIII, que é normalmente transportado no sangue pelo FvW (47). Pacientes com coagulopatia secundária à disfunção renal apresentam níveis mais elevados de prostaciclina $\left(\mathrm{PGI}_{2}\right)$, um vasodilatador e inibidor de agregação plaquetária (48).

Diferentemente do que é descrito na literatura, de que a disfunção renal provoca redução da agregação e adesão plaquetária, a análise da função plaquetária pelo Impact-R da nossa casuística não mostrou redução nos parâmetros AS e SC nos diferentes graus de IRA, demonstrando que a disfunção renal, não piorou a função plaquetária. Pelo contrário, cabe salientar que o resultado do parâmetro AS, que mede a agregação plaquetária, estava no limite superior da normalidade no grupo sem IRA e se manteve elevado nos diversos graus de disfunção renal. Quanto ao parâmetro SC, o resultado foi até maior no grupo que apresentou IRA AKIN3, comparado com o grupo sem IRA, representando maior adesão plaquetária.

Os valores de referência dos parâmetros AS e SC são baseados em condições normais de hemoglobina, hematócrito e número de plaquetas. Anemia, hematócrito baixo e número de plaquetas reduzidos resultam em 
valores de referência de AS e SC menores. Em nossa população estudada, cujos valores de hemoglobina e hematócrito estão reduzidos e número de plaquetas também reduzidos principalmente nos grupo sem IRA e AKIN1 (mas sem diferença estatística com os grupos AKIN2 e AKIN3), o que se esperava, portanto, era uma redução dos parâmetros AS e SC. Assim, os resultados de AS e SC no limite superior de referência, ou até acima da referência, representa uma hiperadesividade e hiperagregabilidade plaquetária em nossos pacientes. Essa hiper-reatividade plaquetária pode ser secundária à interação entre plaquetas e o tumor. Além disso, outros mecanismos propostos para explicar o aumento da ativação plaquetária em pacientes oncológicos são: a geração de trombina induzida pelo tumor, produção de ADP pelo tumor e níveis elevados de fator de vonWillebrand $(51,52,53)$.

O fator de vonWillebrand participa da hemostasia secundária, transportando o fator VIII na circulação, que, quando livre, é rapidamente inativado. Desta forma, a dosagem do fator VIII poderá mostrar indiretamente os níveis de FvW. Em nosso estudo, a dosagem do fator VIII estava aumentado em todos os grupos estudados, representando níveis elevados de FvW, o que promoveria maior adesão e agregação plaquetária.

Testes de coagulação convencionais, tais como TP, TT e TTPa são utilizados de forma rotineira na prática clínica para avaliar o perfil de hemostasia. Entretanto, estes testes revelam apenas o componente da hemostasia in vitro, sendo portanto maus preditores para sangramento, fazendo com que seja hiperestimada a necessidade de transfusão sanguínea $(54,55)$. O resultado da análise da hemostasia por TEG difere dos testes 
convencionais, uma vez que a TEG analisa todas as etapas da coagulação, simulando o que realmente acontece in vivo. Estudos têm demonstrado a diminuição da necessidade de transfusão em procedimentos cirúrgicos após a análise da hemostasia através da TEG (56), comparados com aqueles que se baseiam nos resultados dos testes de coagulação (TP, TT e TTPa).

Em nosso estudo, os resultados dos testes convencionais de coagulação (TP, TT, TTPa) também mostraram-se alterados no grupo com IRA, comparado com o grupo sem IRA. O TP é dependente da integridade dos fatores VII, V, II e X. Foi observado que o TP está mais alargado no grupo que apresentou IRA, comparado com o grupo sem IRA, e que o grupo AKIN3 apresentou o TP mais alargado entre os grupos, representando maior deficiência dos fatores de coagulação. Essa deficiência de fatores de coagulação é consequente à própria sepse, ao estado inflamatório e ao consumo dos fatores de coagulação (57).

Andersen e cols. estudaram a hemostasia em pacientes com sepse ou choque séptico através de testes convencionais de coagulação e tromboelastometria (ROTEM) e observaram que apesar dos testes convencionais mostrarem alteração nos parâmetros de coagulação, o resultado do ROTEM estava dentro dos limites da normalidade. No mesmo estudo, foi observado que mais de um terço das transfusões de plasma fresco não tiveram indicação clínica, exceto pela alteração dos resultados nos testes convencionais de coagulação. Nesse contexto, pelo fato da tromboelastometria apresentar resultado normal, a transfusão de plasma fresco poderia ter sido evitada (58). 
Apesar dos testes de coagulação convencionais em nosso estudo mostrarem alteração da coagulação (hipocoagulação), a análise da hemostasia global através da tromboelastografia não mostrou alteração em nenhum grupo. A justificativa para esse resultado normal pela tromboelastografia é de que a hiperativação plaquetária, conforme visto anteriormente, mantém a normalidade da hemostasia global, apesar da deficiência dos fatores de coagulação.

A nossa casuística mostrou redução da geração de trombina pelo reagente PPP-5pM (ETP-5pM) no grupo que apresentou IRA AKIN2 e AKIN3, comparado com o grupo sem IRA $(p<0,05)$. $O$ valor reduzido da geração de trombina associado ao D-dímero elevado (produto de degradação da fibrina), principalmente no grupo com IRA AKIN3 pode ser explicado pela hiperativação do sistema de coagulação. De acordo com estudos em modelos animais e em humanos, a sepse induz hipercoagulabilidade através da ativação do fator tecidual $(59,60)$ e da hipofibrinólise através da liberação de PAl-1 (plasminogen activator inhibitor-1) (61). A hiperativação do sistema de coagulação, juntamente com a sepse e inflamação, leva ao consumo dos fatores de coagulação que, por sua vez, resulta na menor disponibilidade de substrato para formação de trombina.

O desenvolvimento de injúria renal aguda (IRA) contribui significativamente para o aumento da morbidade e mortalidade dos pacientes em Unidade de Terapia Intensiva (UTI), além do aumento do custo de tratamento (62). A incidência de IRA varia de $35 \%$ a $70 \%$, em pacientes na UTI 
(63). Apesar do progresso do tratamento da IRA nos últimos 50 anos, a mortalidade permanece a mesma, por volta dos $50 \%$ (64).

Na casuística do nosso estudo, os dados foram compatíveis com os da literatura: a incidência de IRA foi de $68 \%$ e a mortalidade nos pacientes que desenvolveram IRA foi superior àquela observada nos pacientes do grupo sem IRA (41,3\% no grupo sem IRA vs. $76,5 \%$ no grupo AKIN1 vs. $84 \%$ no grupo AKIN2 vs. $82,1 \%$ no grupo AKIN3).

Observou-se também em nosso trabalho, que o maior tempo de internação em UTI está associado à maior chance de óbito, apresentando OR de 1,15 (IC: 1,06 - 1,24), assim como o uso de vasopressina e de ventilação mecânica. Esse aumento na chance de óbito deve ser secundário à maior gravidade clínica e pior condição hemodinâmica. O uso de noradrenalina e dobutamina não estava associado com aumento de mortalidade.

Em nosso estudo, o nível sérico de albumina estava baixo em todos os grupos. Diversos estudos mostram que há uma relação inversamente proporcional da concentração sérica de albumina com a mortalidade. A concentração de albumina é um indicador bastante sensível para a gravidade da doença, sendo um preditor independente para a mortalidade $(65,66)$.

O consenso atual recomenda que pacientes críticos em UTI devem ter sua glicemia controlada entre 72 e $180 \mathrm{mg} / \mathrm{dL}$ (67). Sabe-se que a hiperglicemia é fator independente associado à mortalidade (68).

Em pacientes críticos, o aumento do lactato está associado à gravidade da alteração hemodinâmica e possui correlação com falência de órgãos e 
mortalidade $(67,69)$. Em nossa casuística, o nível de lactato está elevado em todos os grupos, o que pode ter contribuído para o aumento da mortalidade.

Comorbidades, tais como, hipertensão arterial, diabetes mellitus, insuficiência coronariana e insuficiência cardíaca não estiveram associados ao aumento da mortalidade em nosso estudo.

Pelo modelo de regressão logística multivariada, observou-se que 4 variáveis influenciaram a mortalidade dos pacientes: ventilação mecânica, proteína C reativa (PCR), geração de trombina ETP-5pM e IRA.

Em nossa casuística, pacientes que fizeram uso de ventilação mecânica apresentaram chance de óbito 12,5 vezes em comparação com pacientes que não necessitaram de ventilação mecânica. $O$ fato de haver necessidade de suporte ventilatório reflete o grau de gravidade clínica. Além disto, a ventilação mecânica per se pode levar à lesão pulmonar induzida pelo ventilador, secundária à hiperdistensão alveolar e atelectasia cíclica. Por conta disso, estratégia ventilatória protetora foi desenvolvida a fim de reduzir o risco desta lesão (70). Entretanto, apesar do progresso nos cuidados dos pacientes críticos e o melhor entendimento da fisiopatologia da lesão pulmonar, a mortalidade permanece elevada.

O aumento de $1 \mathrm{mg} / \mathrm{dl}$ na PCR acarretou aumento de $1 \%$ na chance de óbito. No presente estudo, a proteína $\mathrm{C}$ reativa $(\mathrm{PCR})$ estava elevada em todos os grupos. A PCR é uma proteína de fase aguda e está elevada em situações, tais como, infecção, trauma, isquemia e inflamação. É frequentemente utilizada em UTI como marcador de sepse. Em estudo realizado por Lobo e cols., níveis 
elevados de PCR em UTI estava associado ao aumento do risco de falência de órgãos e óbito (71).

O aumento de 100 nmol na geração de trombina ETP-5pM resultou na redução de 18,1\% na chance de óbito, apresentando OR de 0,819 (Cl: 0,673 0,996). Esse resultado condiz com o que se encontra na literatura. Em estudo realizado por Massion e cols., foi demonstrada que a deficiência da geração de trombina estava associada a maior mortalidade intra-hospitalar (72).

Pacientes com qualquer grau de disfunção renal (AKIN1, AKIN2 ou AKIN3) apresentaram chance de óbito 3,11 vezes em comparação com pacientes sem IRA. É bem conhecido que a insuficiência renal aguda é uma complicação frequente em pacientes críticos, e também um fator de risco independente para mortalidade (73).

Algumas limitações apresentadas em nosso estudo incluem: estudo unicêntrico, o que poderia comprometer a generalização dos resultados e pacientes oncológicos, e portanto, os resultados da análise da função plaquetária, o comportamento dos testes de coagulação e da hemostasia global podem ser diferentes em pacientes não oncológicos. 


\section{CONCLUSÕES}

A. A injúria renal aguda em pacientes críticos oncológicos com sepse ou choque séptico está associada ao alargamento dos testes de coagulação convencionais (TP, TT, TTPa), devido à deficiência de alguns fatores de coagulação. Entretanto, a tromboelastografia, que analisa a hemostasia global do paciente, apresentou resultado normal devido à hiperativação da função plaquetária.

B. Em nossos pacientes, o acúmulo de toxinas urêmicas devido à injúria renal aguda, não levou à piora da função plaquetária. Pelo contrário, houve até aumento na agregação e adesão plaquetárias.

C. O resultado da hemostasia global depende da interação de várias vias responsáveis pela coagulação. Apesar dos grupos AKIN2 e AKIN 3 terem apresentado menor geração de trombina, a hemostasia global avaliada pela tromboelastografia estava normal.

D. A necessidade de ventilação mecânica, o nível de proteína $C$ reativa, a geração de trombina expressa pela ETP-5pM e injúria renal aguda são fatores preditores independentes de mortalidade nesta população. 


\section{REFERÊNCIAS}

1. Blom JW, Doggen CJM, Osanto S, Rosendaal FR. Malignancies, prothrombotic mutations, and the risk of venous thrombosis. JamaJournal of the American Medical Association. 2005 Feb;293(6):715-22.

2. Carrier M, Le Gal G, Wells PS, Fergusson D, Ramsay T, Rodger MA. Systematic review: The trousseau syndrome revisited: Should we screen extensively for cancer in patients with venous thromboembolism? Annals of Internal Medicine. 2008 Sep;149(5):323-W69.

3. Lyman GH, Khorana AA. Cancer, Clots and Consensus: New Understanding of an Old Problem. Journal of Clinical Oncology. 2009 Oct;27(29):4821-6.

4. Heit JA, O'Fallon WM, Petterson TM, Lohse CM, Silverstein MD, Mohr $\mathrm{DN}$, et al. Relative impact of risk factors for deep vein thrombosis and pulmonary embolism - A population-based study. Archives of Internal Medicine. 2002 Jun;162(11):1245-8.

5. Khorana AA, Francis CW, Culakova E, Fisher RI, Kuderer NM, Lyman $\mathrm{GH}$. Thromboembolism in hospitalized neutropenic cancer patients. Journal of Clinical Oncology. 2006 Jan;24(3):484-90.

6. Khorana AA, Francis CW, Culakova E, Kuderer NM, Lyman GH. Thromboembolism is a leading cause of death in cancer patients receiving outpatient chemotherapy. Journal of Thrombosis and Haemostasis. 2007 Mar;5(3):632-4.

7. Sousou T, Khorana AA. New Insights Into Cancer-Associated Thrombosis. Arteriosclerosis Thrombosis and Vascular Biology. 2009 Mar;29(3):316-20.

8. Khorana AA, Connolly GC. Assessing Risk of Venous Thromboembolism in the Patient With Cancer. Journal of Clinical Oncology. 2009 Oct;27(29):4839-47.

9. Komrokji RS, Uppal NP, Khorana AA, et al. Venous thromboembolism in patients with diffuse large B-cell lymphoma. Leuk Lymphoma 47: 10291033. 2006.

10. Numico G, Garrone O, Dongiovanni V, et al. Prospective evaluation of major vascular events in patients with nonsmall cell lung carcionoma treated with cisplatin and gemcitabine. Cancer 103: 994-999. 2005.

11. Blom JW, Vanderschoot JPM, Oostindier MJ, Osanto S, van der Meer FJM, Rosendaal FR. Incidence of venous thrombosis in a large cohort of 
66329 cancer patients: results of a record linkage study. Journal of Thrombosis and Haemostasis. 2006 Mar;4(3):529-35.

12. Heit JA, Silverstein MD, Mohr DN, Petterson TM, O'Fallon WM, Melton LJ. Risk factors for deep vein thrombosis and pulmonary embolism - A population-based case-control study. Archives of Internal Medicine. 2000 Mar;160(6):809-15.

13. Khorana AA, Francis CW, Culakova E, Kuderer NM, Lyman GH. Frequency, risk factors, and trends for venous thromboembolism among hospitalized cancer patients. Cancer. 2007 Nov;110(10):2339-46.

14. Kroger K, Weiland D, Ose C, Neumann N, Weiss S, Hirsch C, et al. Risk factors for venous thromboembolic events in cancer patients. Annals of Oncology. 2006 Feb;17(2):297-303.

15. Nalluri SR, Chu D, Keresztes R, Zhu XL, Wu SH. Risk of Venous Thromboembolism With the Angiogenesis Inhibitor Bevacizumab in Cancer Patients A Meta-analysis. Jama-Journal of the American Medical Association. $2008 \mathrm{Nov} ; 300(19): 2277-85$.

16. Bohlius J, Wilson J, Seidenfeld J, Piper M, Schwarzer G, Sandercock J, et al. Recombinant human erythropoietins and cancer patients: Updated meta-analysis of 57 studies including 9353 patients. Journal of the National Cancer Institute. 2006 May;98(10):708-14.

17. Khorana AA, Francis CW, Blumberg N, Culakova E, Refaai MA, Lyman $\mathrm{GH}$. Blood Transfusions, Thrombosis, and Mortality in Hospitalized Patients With Cancer. Archives of Internal Medicine. 2008 Nov;168(21):2377-81.

18. Agnelli G, Bolis G, Capussotti L, Scarpa RM, Tonelli F, Bonizzoni E, et al. A clinical outcome-based prospective study on venous thromboembolism after cancer surgery - The @RISTOS project. Annals of Surgery. 2006 Jan;243(1):89-95.

19. Verso M, Agnelli G. Venous thromboembolism associated with long-term use of central venous catheters in cancer patients. Journal of Clinical Oncology. 2003 Oct;21(19):3665-75.

20. Tesselaar MET, Ouwerkerk J, Nooy MA, Rosendaal FR, Osanto S. Risk factors for catheter-related thrombosis in cancer patients. European Journal of Cancer. 2004 Oct;40(15):2253-9.

21. Lee AYY, Levine MN, Butler G, Webb C, Costantini L, Gu CS, et al. Incidence, risk factors, and outcomes of catheter-related thrombosis in adult patients with cancer. Journal of Clinical Oncology. 2006 Mar;24(9):1404-8. 
22. Connolly GC, Chen R, Hyrien O, Mantry P, Bozorgzadeh A, Abt $P$, et al. Incidence, risk factors and consequences of portal vein and systemic thromboses in hepatocellular carcinoma. Thrombosis Research. 2008;122(3):299-306.

23. Khorana AA, Francis CW, Culakova E, Lyman GH. Risk factors for chemotherapy-associated venous thromboembolism in a prospective observational study. Cancer. 2005 Dec;104(12):2822-9.

24. Khorana AA, Kuderer NM, Culakova E, Lyman GH, Francis CW. Development and validation of a predictive model for chemotherapyassociated thrombosis. Blood. 2008 May;111(10):4902-7.

25. Tesselaar MET, Romijn F, Van der Linden IK, Prins FA, Bertina RM, Osanto S. Microparticle-associated tissue factor activity: a link between cancer and thrombosis? Journal of Thrombosis and Haemostasis. 2007 Mar;5(3):520-527.

26. Sallah S, Husain A, Sigounas V, Wan J, Turturro F, Sigounas G, et al. Plasma coagulation markers in patients with solid tumors and venous thromboembolic disease receiving oral anticoagulation therapy. Clinical Cancer Research. 2004 Nov;10(21):7238-43.

27. Hoffman M. A cell-based model of coagulation and the role of factor VIla. Blood Reviews. 2003, 17: S1-S5.

28. Innerhofer P, Kienast J. Principles of perioperative coagulopathy. Best Practice \& Research Clinical Anaesthesiology. 24 (2010); 1 - 14.

29. Manual de diagnóstico laboratorial das Coagulopatias Hereditárias e Plaquetopenias. Ministério da Saúde. 2012.

30. Wells PS, Anderson DR, Rodger M, Forgie M, Kearon C, Dreyer J, et al. Evaluation of D-dimer in the diagnosis of suspected deep-vein thrombosis. New England Journal of Medicine. 2003 Sep;349(13):122735.

31.D. Varon, N. Savion. Cone and Platelet Analyzer, Platelets (A.D. Michelson, ed). Academic Press. 2002; 337-345.

32. Sorensen B, Ingerslev J. Tailoring haemostatic treatment to patient requirements - an update on monitoring haemostatic response using thromboelastography. Haemophilia. 2005, 11, suppl 1, 1-6.

33. Luddington RJ. Thrombelastography/thromboelastometry. Clinical and Laboratory Haematology. 2005 Apr;27(2):81-90.

34. Luddington RJ. Thromboelastography / thromboelastometry. Clin. Lab. Haem. 2005, 27, 81-90. 
35. Thromboelastograph Haemostasis Analyser - user's manual. Haemoscope Corporation, Niles, IL, USA. www.hamoecope.com

36. Thrombin Generation. www.thrombinoscope.com/thrombin-generation

37. Karamlou K, Nichols DJ, Nichols CR. Intensive care unit outcomes in elderly cancer patients. Critical Care Clinics. 2003;19(4):657-.

38. Soares M, Carvalho MS, Salluh JIF, Ferreira CG, Luiz RR, Rocco JR, et al. Effect of age on survival of critically ill patients with cancer. Critical Care Medicine. 2006;34(3):715-21.

39. Dennen P, Douglas IS, Anderson R. Acute kidney injury in the intensive care unit: An update and primer for the intensivist. Critical Care Medicine. 2010;38(1):261-75.

40. Soares M, Salluh JIF, Carvalho MS, Darmon M, Rocco JR, Spector N. Prognosis of critically ill patients with cancer and acute renal dysfunction. Journal of Clinical Oncology. 2006;24(24):4003-10.

41. Mehta RL, Chertow GM. Acute renal failure definitions and classification: Time for change? Journal of the American Society of Nephrology. 2003;14(8):2178-87.

42. Ostermann M, Chang R, Riyadh ICUPUG. Correlation between the AKI classification and outcome. Critical Care. 2008;12(6).

43. Abelha FJ, Botelho $M$, Fernandes $V$, Barros $H$. Determinants of postoperative acute kidney injury. Critical Care. 2009;13(3).

44. Chertow GM, Burdick E, Honour M, Bonventre JV, Bates DW. Acute kidney injury, mortality, length of stay, and costs in hospitalized patients. Journal of the American Society of Nephrology. 2005;16(11):3365-70.

45. Noris M, Remuzzi G. Uremic bleeding: Closing the circle after 30 years of controversies? Blood. 1999;94(8):2569-74.

46. Riesman D. Hemorrhages in the course of Bright's disease, with especial reference to the occurrence of a hemorrhagic diathesis of nephritic origin. American Journal of the Medical Sciences. 1907;134:709-16.

47. Hedges SJ, Dehoney SB, Hooper JS, Amanzadeh J, Busti AJ. Evidencebased treatment recommendations for uremic bleeding. Nature Clinical Practice Nephrology. 2007;3(3):138-53.

48. Remuzzi G, Mecca G, Cavenaghi AE, Donati MB, Gaetano GD. PROSTACYCLIN-LIKE ACTIVITY AND BLEEDING IN RENAL-FAILURE. Lancet. 1977;2(8050):1195-7. 
49. Vanholder R, De Smet R, Glorieux G, Argiles A, Baurmeister U, Brunet $P$, et al. Review on uremic toxins: Classification, concentration, and interindividual variability. Kidney International. 2003;63(5):1934-43.

50. Elliot JM et al. Erythropoetin mimics the acute phase response in critical illness. Crit Care, v7, n3, R35-40. 2003.

51. Uchiyama $\mathrm{T}$ et al. Studies on the pathogenesis of coagulopathy in patients with arterial thromboembolism and malignancy. Thromb Res. 1990; 59(6):955.

52. Sweeney JD et al. vonWillebrand fator in head and neck câncer. Cancer. 1990; 66(11):2387.

53. Nash GF et al. Platelets and cancer. Lancet Oncol. 2002; 3(7):425.

54. Segal JB; Dzik WH. Paucity of studies to suport that abnormal coagulation test results predict bleeding in the setting of invasive procedures: an evidence-based review. Transfusion 2005; 45:1413-25.

55. Chowdary $P$ et al. Efficacy of standard dose and $30 \mathrm{ml} / \mathrm{kg}$ fresh frozen plasma in correcting laboratory parameters of haemostasis in critically ill patients. Br J Haematol 2004; 125:69-73.

56. Romlin BS et al. Intraoperative thromboelastometry is associated with reduced transfusion prevalence in pediatric cardiac surgery. Anesth Analg $2011 ; 112: 30-6$.

57. Wang $\mathrm{Y}$ et al. Dynamic changes in thrombin generation in abdominal sepsis in mice. Whock, vol 42, no 4, 343-349, 2014.

58. Andersen MG et al. Thromboelastometry as a supplementary tool for evaluation of hemostasis in sever sepsis and septic shock. Acta Anaesthesiol Scand 2014; 58:525-533.

59. Amaral A, Opal SM, Vincent JL. Coagulation in sepsis. Intensive Care Med. 2004; 30:1032-1040.

60. Gando $S$ et al. Activation of the extrinsic coagulation pathway in patients with severe sepsis and septic shock. Crit Care Med. 1998; 26:2005-2009.

61.Degen JL, Bugge TH, Gguen JD. Fibrin and fibrilolysis in infection and host defense. J Thromb Haemost. 2007; 5 (Suppl 1): 24-31.

62. Thakar CV et al. Incidence and outcomes of acute kidney injury in intensive care units: A Veterans Administration study. Crit Care Med 2009. Vol 37, N9. 2552-2558. 
63. Christopher KB. Excess mortality attributable to acute kidney injury. Crit Care Med. April 2014. Vol 42. Issue 4. 992-993.

64. Ympa et al. Has mortality from acute renal failure decreased? A systematic review of the literature. Am J Med. 2005 Aug; 118(8):827-32.

65. Goldwasser P, Feldman J. Association of sérum albumin and mortality risk. J CLin Epidemiol. Jun; 50(6): 693-703. 1997.

66. Jellinge ME et al. Hypoalbuminemia is a Strong predictor of 30-day allcause mortality in acutely admitted medical patients: a prospective, observational, cohort study. PloS One. Aug 2014, vol 9, issue 8

67. Van Beest PA, Spronk PE. Lactate and Glucose in critically ill patients: what goesa round, comes around. Critical Care Medicine; vol 42(6), june 2014, 1545-1546.

68. Christiansen $\mathrm{C}$ et al. Hyperglicaemia and mortality in critically ill patients. A prospective study. Intensice Care Med. 2004; 30:1685-1688.

69. Jansen TC et al. Blood lactate monitoring in critically ill patients: a systematic health technology assessment. Crit Care Med. 2009; 37:28272839.

70. Amato et al. Effect of a protective-ventilation strategy on mortality in the acute respiratory distress syndrome. N Eng J Med 1998; 338:347-354.

71. Lobo SM et al. C-reactive protein levels correlate with mortality and organ failure in critically ill patients. Chest. 2003 Jun; 123(6):2043-9.

72. Massion et al. Persistent hypocoagulability in patients with septic shock predicts greater hospital mortality: impact of impaired thrombin generation. Intensive Care Med. 2012; 38:1326-1335.

73. Weisbord SD, Palevsky PM. Acute renal failure in the intensive care unit. Semin Respir Crit Care Med. 2006 Jun; 27(3): 262-73. 